\title{
THESIS
}

\section{PATTERNS AND CORRELATES OF CAREGIVER SATISFACTION WITH YOUNG CHILDREN'S PARTICIPATION IN HOME ACTIVITIES}

\author{
Submitted by \\ Lauren Nicole Nale \\ Department of Occupational Therapy \\ In partial fulfillment of the requirements \\ For the Degree of Master of Science \\ Colorado State University \\ Fort Collins, Colorado
}

Summer 2016

Master's Committee

Advisor: Mary Khetani

David Greene

Lisa Daunhauer 
Copyright by Lauren Nicole Nale 2016

All Rights Reserved 


\section{ABSTRACT \\ PATTERNS AND CORRELATES OF CAREGIVER SATISFACTION WITH YOUNG CHILDREN'S PARTICIPATION IN HOME ACTIVITIES}

Young children's participation in home activities is an important indicator of their health and well-being and also facilitates development in social, physical, and emotional skills. Prior studies have shown that young children with disabilities and delays experience participation restrictions. Some young children with disabilities and delays qualify for services to improve their participation in activities. Therefore, service providers, such as occupational therapists, can benefit from context-specific information on trends and correlates of caregiver concern (i.e., dissatisfaction) with children's participation. This detailed information can help to direct familycentered care towards improved participation.

The Young Children's Participation and Environment Measure (YC-PEM) is a caregiver questionnaire that assesses context-specific information about areas of caregiver concern (i.e., dissatisfaction) with young children's participation in specific activities, as well as perceived environmental supports and barriers for participation in a specific setting. A recent study leveraging YC-PEM data showed that discrepancies in daycare/preschool participation between young children with and without disabilities, including caregiver desire for change (i.e., dissatisfaction), can be detected in the early childhood period. This study further leverages the YC-PEM to examine disparities in caregiver satisfaction with young children's participation in the home. The home is a significant context given that it is where young children spend a majority of their time and where early childhood interventions often occur. Towards this end, the purpose of this study is three-fold: 1) to characterize common areas of caregiver dissatisfaction with young children's home participation, 2) to examine common type(s) of caregiver change 
desired with their young child's home participation, and 3) to evaluate child, family, and environmental correlates of caregiver dissatisfaction with young children's participation in home activities.

Study results suggest no statistically significant disability group differences in caregiver concern with young children's participation in home-based activities. Cleaning up is the most common home activity of concern for caregivers of young children with and without disabilities or delays. Despite this commonality, caregivers of young children with disabilities or delays more often reported a desire for change in their child's participation in non-discretionary activities, such as basic care routines and household chores. Additionally, caregivers of children with disabilities or delays most commonly desired their child to be 'more helpful' when participating in these non-discretionary activities. Finally, the presence of a disability or delay, annual household income of $>\$ 60,000$, and lower levels of perceived environmental support were significant correlates of caregiver desire for change in young children's participation at home.

Study findings suggest that a majority of caregivers of young children with and without disabilities and delays have similar priorities for improving their child's involvement in nondiscretionary activities at home. In addition, results suggest that caregiver satisfaction with young children's participation at home is influenced by perceptions of environmental support within the home, as well as the child's disability status and household income. Future research should examine similar correlates of young children's frequency and involvement in home activities, as well as desire for change in out-of-home contexts such as community. This knowledge may allow practitioners to identify appropriate intervention targets for optimizing participation in the home environment. 


\section{ACKNOWLEDGEMENTS}

First and foremost, I would like to thank my hardworking and dedicated parents for always supporting and encouraging me and raising me in a way that gave me the ability to achieve my dreams and be the person I am today. I am also extremely grateful for my three beautiful, smart, and loving sisters, Jennifer, Andrea, and Michelle, who keep life interesting and are my best friends and confidants. I would also like to thank Thomas Moran for always reminding me of what I am capable of and for handling all my stress in a loving way. I would also like to thank all of my friends in the OT program for their support throughout my thesis process, and especially for listening to my dilemmas and giving me advice when I needed it. I also want to acknowledge my past and present Children's Participation and Environment Research Lab (CPERL) team members Kristen, Tanya, Jiang, Cara, and Ryan for their constructive feedback on my thesis and for making the lab environment a great place to work.

I would like to thank all my committee members, Dr. David Greene, Dr. Lisa Daunhauer, and Dr. Beth McManus, for their thoughtful insights, time spent problem solving with me, and also for all their feedback on my thesis. I would also like to thank someone who I consider to be an honorary committee member, Erin Albrecht, who assisted me in developing my statistical analyses and provided me with multiple resources to be successful.

I also want to extend a huge thank you to my mentor, Dr. Mary Khetani for giving me the opportunity to work with her in CPERL and on my thesis. I am extremely grateful for the many hours that Mary has spent unraveling thesis dilemmas with me, developing my skills as a researcher, providing me with opportunities that I had never anticipated, and helping me to develop professionally. I would also like to thank the National Institutes of Health who funded the collection of data and my time for thesis completion (\#K12 HD055931). 


\section{TABLE OF CONTENTS}

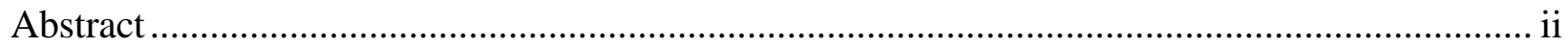

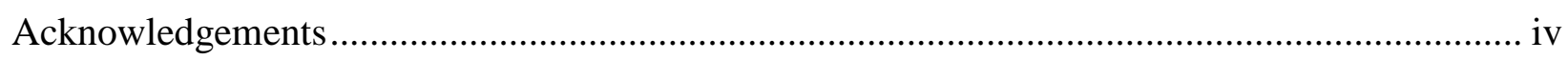

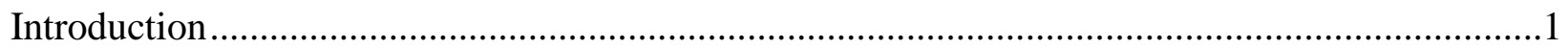

Measuring Children's Participation: Issues and Challenges ........................................2

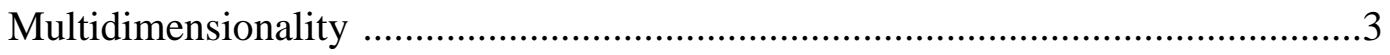

Participation-environment relationship...................................................5

Applying Children's Participation Assessments to Examine Patterns ............................

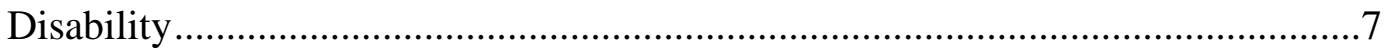

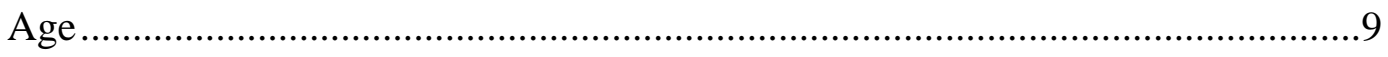

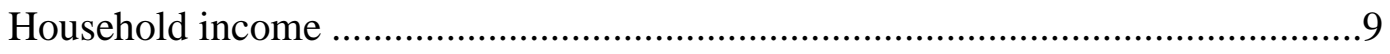

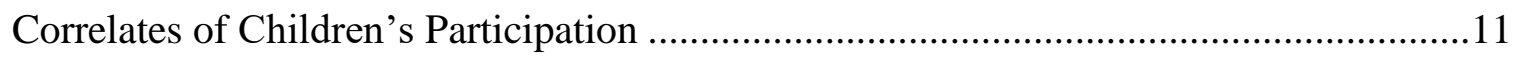

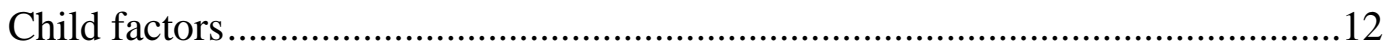

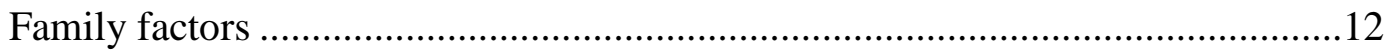

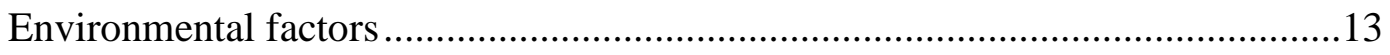

Participation and Environment Measurement (PEM) Approach ...................................14

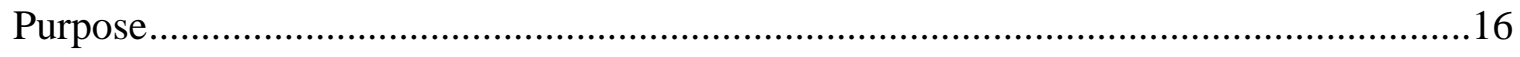

Relevance of Thesis to Occupation and Rehabilitation Science (ORS) .........................18

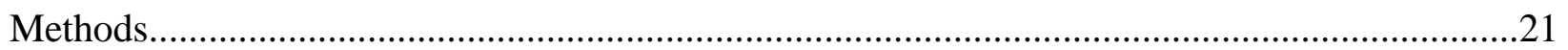

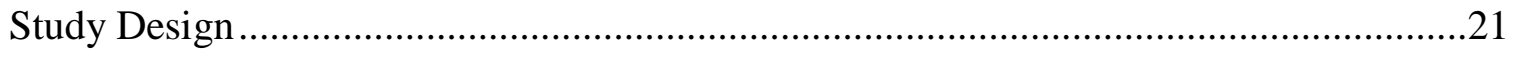

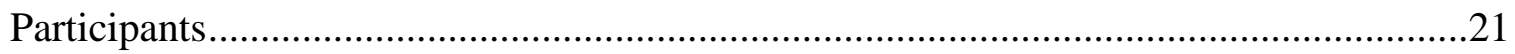

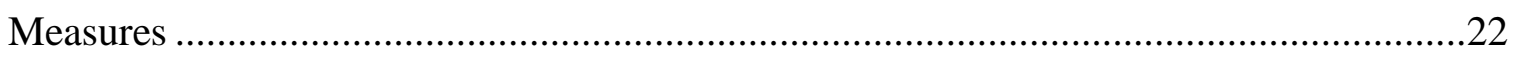

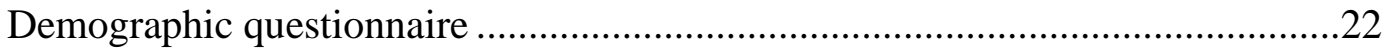




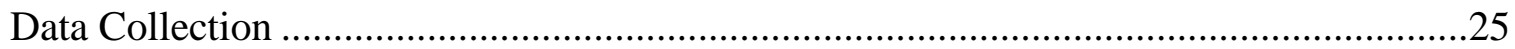

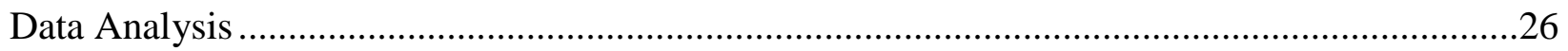

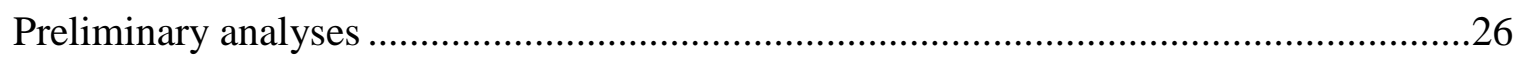

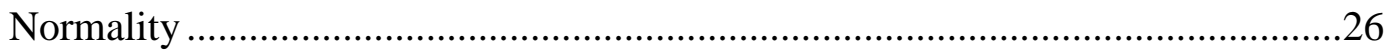

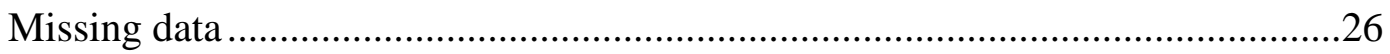

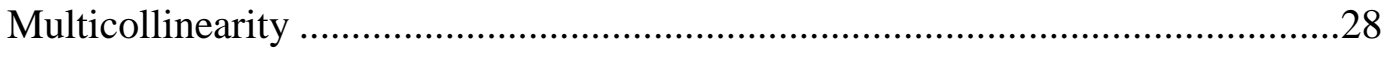

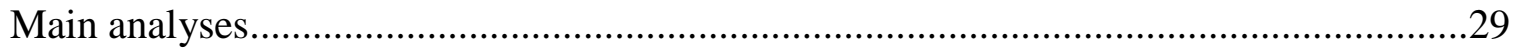

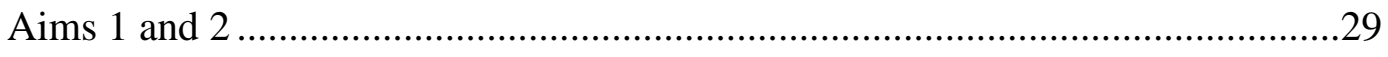

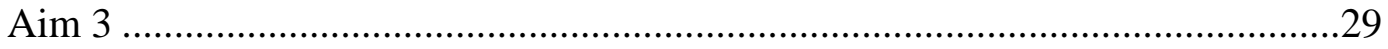

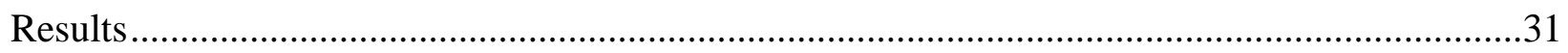

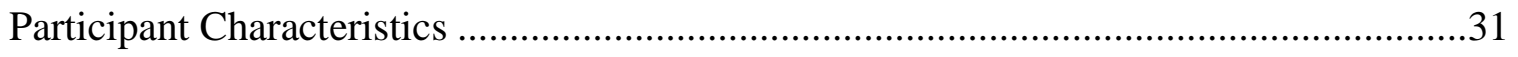

Aim 1: Areas of Caregiver Dissatisfaction with Young Children's Home Participation ..34 Aim 2: Type(s) of Caregiver Change Desired with Young Children's Home Participation.

Aim 3: Correlates of Caregiver Dissatisfaction with Young Children's Home

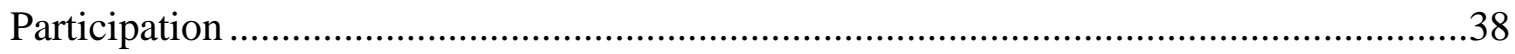

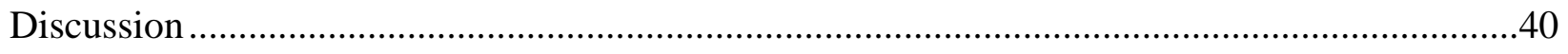

Aim 1: Areas of Caregiver Dissatisfaction with Young Children's Home Participation..41 Aim 2: Type(s) of Caregiver Change Desired with Young Children's Home Participation.

Aim 3: Correlates of Caregiver Dissatisfaction with Young Children's Home 
Participation

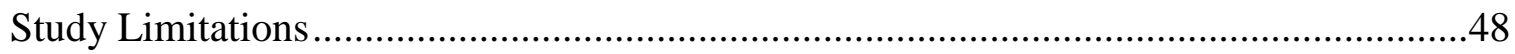

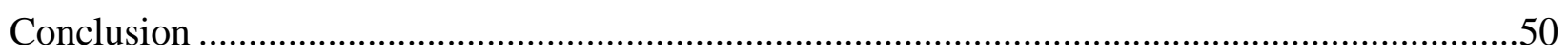

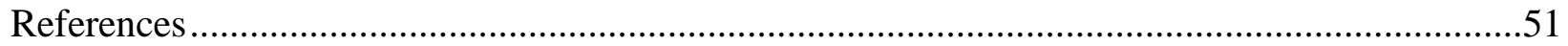

Appendix A: Example of Home Participation Section in YC-PEM........................................63

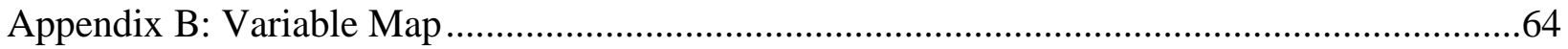




\section{Introduction}

Participation in activities is an indicator of health and well-being for young children (Law, 2002; The United Nations Children's Fund [UNICEF], 2013; World Health Organization [WHO], 2007; WHO \& The World Bank, 2011). Young children's participation may also facilitate the early development of motor, cognitive, emotional, and social capacities (Dunst, Hamby, Trivette, Raab, \& Bruder, 2002; Hofferth \& Sandberg, 2001; Larson, 2000; Larson \& Verma, 1999). For example, Trevlas, Matsouka, and Zachopoulou (2003) found a positive association between young children's participation in play and the breadth and fluidity of their motor movement. Similarly, Phillips and Hogan (2014) reported that young children, ages 4 to 5, who experienced low frequency and diversity (i.e., the number of activities a child participates in) when participating in recreational activities were 1.5 to 2 times more likely to have poor social competence.

Young children with developmental disabilities and delays experience difficulties when participating in activities (Khetani, Graham, \& Alvord, 2013c; Khetani, Orsmond, Cohn, Law, \& Coster, 2012b). In fact, participation is a primary service-related outcome for those children who are deemed eligible for early intervention, outpatient and inpatient pediatric rehabilitation, and early childhood special education (American Occupational Therapy Association (AOTA), n.d.; Hebbeler et al., 2007; Individuals with Disabilities Education Improvement Act of 2004; Majnemer, 2009). Nearly one-fifth of occupational therapists nationwide are employed in these pediatric settings (National Board for Certification in Occupational Therapy, 2012). Pediatric occupational therapists are typically members of multidisciplinary teams where they are able to contribute their expertise about young children's participation in occupation (AOTA, 2014). 


\section{Measuring Children's Participation: Issues and Challenges}

To ensure care quality, occupational therapists need valid and feasible ways to assess for problems in participation in order to guide decisions about when and how to intervene with young children and their families. However, researchers have debated how to operationalize the concept of participation so that problems of this type can be adequately documented when working with pediatric and adult populations (Coster \& Khetani, 2008; Hammel et al., 2008; Hemmingsson \& Jonsson, 2005).

Both the International Classification of Functioning, Disability and Health (ICF) (WHO, 2001) and International Classification of Functioning, Disability and Health: Children and Youth Version (ICF-CY) (WHO, 2007) represent a significant advance relative to prior models of disability that primarily focused on "impairments" and "handicaps." However, these international frameworks do not adequately define the concept of participation so that it can be measured and assessed. According to the ICF-CY, participation is defined as "involvement in a life situation" (WHO, 2007, p. 9). Based on this broad definition, it is not clear what constitutes a life situation for a child, or what it means for a child to be involved in a life situation (Coster \& Khetani, 2008; McConachie, Colver, Forsyth, Jarvic, \& Parkinson, 2006).

In the absence of frameworks to guide measure development, researchers often draw upon prior literature to inform the design of an instrument. However, the adult literature on participation does not provide clear guidance for measure development related to children. Participation for adults has been conceptualized as the ability to fulfill socially defined roles (Eyssen, Steultjens, Dekker, \& Terwee, 2011; Hammel et al., 2008; Wade \& Halligan, 2007; Whiteneck \& Dijkers, 2009). However, it is difficult to define children's participation according to social roles because their participation in most, if not all, activities typically involves the 
presence and engagement of other individuals, such as the child's caregiver, sibling, or friend. Furthermore, children's participation is often socially mandated (e.g., school policies shaping how children participate in school-based activities, or caregiver expectations and preferences shaping participation in home-based activities) (Coster \& Khetani, 2008; Coster et al., 2012). Hence, it has been proposed that children's participation refers to involvement in organized sets and sequences of activities that typically involve the presence and engagement of others (Coster \& Khetani, 2008; Khetani, Cohn, Orsmond, Law, \& Coster, 2013a).

In contrast to the adult literature, there are two recurrent themes in the pediatric literature around defining the concept of participation for children: 1) participation is a multidimensional construct with both objective and subjective dimensions (Bedell, Khetani, Cousins, Coster, \& Law, 2011; Coster \& Khetani, 2008; Hemmingsson \& Jonsson, 2005) and 2) participation is closely tied to the environment in which a given activity takes place (Anaby et al., 2014; Khetani et al, 2013a; Whiteneck \& Dijkers, 2009).

Multidimensionality. There is a growing consensus that assessments of participation should involve both subjective and objective dimensions because participation is both a personal experience and an observable phenomenon (Coster \& Khetani, 2008; Hemmingsson \& Jonsson, 2005; Imms et al., 2016; WHO, 2007). Problems in participation may not be fully understood if the assessment relies solely on an objective measurement approach (Hammel et al., 2008; Coster \& Khetani, 2008). A major benefit of assessing children's participation in multiple ways is that a service provider can customize an intervention to improve a child's participation because he or she has synthesized knowledge about the child's current level of participation in an activity as well as the client's priorities for change in that activity. 
Subjective assessment of children's participation typically involves caregiver or child self-report of satisfaction or enjoyment (Coster et al., 2012; King et al, 2004; Rosenberg, Jarus, $\&$ Bart, 2010a), or the child or family may be directed to select activities that are most important to them (Bedell, Khetani, Coster, Law, \& Cousins, 2012; King et al, 2004; Mandich, Polatakjko, Miller, \& Baum, 2004). For example, the Children's Assessment of Participation and Enjoyment (CAPE: King et al., 2004) collects subjective information on participation by asking school-aged children about the extent of their enjoyment in a given activity, with responses ranging from 'not at all' to 'love it.' The Preferences for Activities of Children (PAC: King et al., 2004) is a companion instrument to the CAPE that asks a child about their preferences for specific activities. Similarly, researchers developed the Young Children's Participation and Environment Measure (YC-PEM: Khetani, Coster, Law, \& Bedell, 2013b) to ask if caregivers wanted their young children's participation to change, and if so, how (e.g., participate more or less frequently, be more or less involved, and/or do a broader variety of activities).

Objective dimensions of children's participation are typically captured via frequency or intensity estimates (i.e., how often the child participates), as well as involvement estimates (i.e., how helpful and/or interactive their child was when participating in an activity with the caregiver) as reported by the child or caregiver. This dimension has been captured in current informant-reported assessments that examine the child's perception of their participation or the caregiver's perceptions and observations of the child participating in activities (King et al., 2004; Khetani et al., 2013b). For example, the CAPE and the version intended for younger children, Assessment of Preschool Children's Participation (APCP), gathers information from caregivers on their pre-school aged child's participation by showing caregivers drawings of 45 activities and asking them to identify which activities their child participate in and how often they 
participate (King et al., 2004; Law, King, Petrenchik, Kertoy, \& Anaby, 2012b). Similarly, the Children's Participation Questionnaire (CPQ) is a caregiver questionnaire for use with children 4 to 6 years old in which caregivers report on their child's diversity, independence, and intensity of participation (Rosenberg et al., 2010a). Similarly, the Participation and Environment Measure for Children and Youth (PEM-CY: Coster, Law, \& Bedell, 2010) and YC-PEM (Khetani et al., 2013b) both include an assessment of how frequently children participate and how involved the child is when participating in broad types of activities.

Participation-environment relationship. There is growing recognition that environments play a significant role in shaping children's functioning (Anaby et al., 2013; Anaby et al., 2014; Whiteneck \& Dijkers, 2009; WHO, 2001; 2007) and skill development (Bronfenbrenner, 1994). However, there is a need for more theoretically informed measures of children's environments to strengthen clinically relevant research on children's participation (King, 2013). Anaby and colleagues (2013) suggest that greater knowledge about the environment is needed in research on children's participation because environmental factors may be more malleable to change than the child's functional capacities. In addition, prior qualitative studies involving caregivers of children with and without disabilities suggest that caregivers naturally think about and evaluate the qualities of their child's environment in terms of its impact on participation or that participation is appraised with consideration of where the activity takes place (Bedell et al., 2011; Khetani et al., 2013a). Hence, there is potential benefit to evaluating the environment within participation assessments to strengthen the research evidence guiding intervention planning (Coster et al., 2012; Khetani, Bedell, Coster, Cousins, \& Law, 2012a; Khetani, Cliff, Schelly, Daunhauer, \& Anaby, 2014). 
Environmental impact on children's participation has been typically assessed broadly and separately, if it is assessed at all. For example, assessments of school-aged and young children's participation, such as the CAPE and PAC, APCP, Pediatric Activity Card Sort (PACS) have not addressed environmental impact (King et al., 2004; Khetani \& Coster, 2014; Law et al., 2012b). However, the Craig Hospital Inventory of Environmental Factors Children-Parent Version (CHIEF-CP) is one of the first environmental assessments adapted for use with a pediatric population (McCauley et al., 2013). The CHIEF-CP contains 10 items pertaining to environmental barriers that impact the child's participation in a broad sense, and for each item, caregivers report on frequency and magnitude of perceived impact (e.g., How often did your child need someone else's help at preschool, school, or work and could not get it easily?) (McCauley et al., 2013). Additionally, the Craig Hospital Inventory of Environmental Factors (CHIEF), the adult version of the CHIEF-CP, is meant to be used with a participation assessment for adults called the Craig Handicap Assessment and Reporting Technique (CHART) (Whiteneck, Charlifue, Gerhart, Overholser, \& Richardson, 1992; Khetani et al., 2014).

Similarly, developers of participation assessments for children have also created separate assessments to address environmental impact. For example, the Child and Adolescent Scale of Environment (CASE: Bedell \& McDougall, 2013) is intended to be paired with the Child and Adolescent Scale of Participation (CASP: Bedell, 2009), and the Environmental Restriction Questionnaire (ERQ: Rosenberg, Ratzon, Jarus, \& Bart, 2010b) is intended to be paired with the CPQ (Rosenberg et al., 2010a). Alternatively, the PEM-CY (Coster et al., 2010) and YC-PEM (Khetani et al., 2013b) assess for participation and environment within the same instrument. As a result, information on perceived environmental impact is obtained with greater specificity, because caregivers are asked about the perceived impact of a broad range of environmental 
features on participation in a specific setting (e.g. home, school, community). Similarly, the School Function Assessment (SFA: Coster, Deeney, Haltiwanger, \& Haley, 1998) focuses on a subset of environmental factors that impact school participation of children. These assessments, which combine participation and environmental factors into one instrument, allow for greater specificity but are few and far between.

Regardless of their level of specificity, environmental assessments typically address a broad range of factors that are external to the child, such as physical (e.g., amount of space, layout), attitudinal, economic, social (e.g., family, peers), institutional (e.g., school policies), and cultural factors (Law et al. 1999; WHO, 2007). In addition, caregivers have identified resource availability (e.g., time, internet, money) and the cognitive, social, and physical demands of activities as additional facets of environments that can impact a child's participation (Bedell, et al., 2011; Khetani et al., 2013a).

\section{Applying Children's Participation Assessments to Examine Patterns}

Many existing assessments of children's participation have been applied in research to further examine patterns of disparities in children's participation according to the child's disability status, age, and/or household income. Knowledge about disparities in children's participation is essential because it can inform clinical decisions about which clients could benefit from interventions targeting participation.

Disability. Disability status is often indicated by whether the child carries a diagnosis that is known to result in functional deficits (e.g., traumatic brain injury, vision loss) and/or whether the child is receiving services due to developmental diagnosis or delay (e.g., autism spectrum disorder, cerebral palsy). Several studies that utilize the CAPE, show that children with disabilities participate in significantly fewer activities and in more socially isolated out-of-school 
activities (Hilton, Crouch, \& Israel, 2008; Jarus, Lourie-Gelberg, Engel-Yeger, \& Bart, 2011; Ullenhad, Krumlinde-Sundholm, Granlund, \& Almqvist, 2014).

In addition, since most prior studies have focused on children with physical disabilities, it is not clear if these disparities in participation would show up for children with developmental, intellectual, behavioral, and emotional disabilities (Bekung \& Hagberg, 2002; Daunhauer, Gerlach-McDonald, \& Khetani, 2014; Engel-Yeger \& Hamed-Daher, 2013; King et al., 2009; Law et al., 2006). However, more recently, studies utilizing the PEM-CY and YC-PEM involve more diagnostically diverse samples and have confirmed that children with disabilities participate less frequently and are less involved when participating in activities in the home setting (Law et al., 2012a), educational setting (daycare, preschool, school) (Benjamin, LucasThompson, Little, Davies, \& Khetani, 2016; Coster et al., 2013), and community setting (Bedell et al., 2013). However, subgroup analyses of the disability group have not yet been pursued to examine the effect of disability type (i.e., physical versus cognitive disability) on disparities in participation within each setting.

Some researchers have focused on the severity of the child's condition, as opposed to the child's diagnosis, to examine patterns of participation (Colver et al., 2012; Law et al., 2004; Law, Petrenchick, King, \& Hurley, 2007; Tsang, Guo, Fong, Mak, \& Pang, 2012). For example, Orlin and colleagues (2010) used the CAPE with school-aged children with cerebral palsy and found that higher motor functioning was positively associated with greater participation in physical activities. Similarly, Khetani and colleagues (2013c) found that for preschoolers with developmental disabilities and delays, the child's functional abilities were negatively correlated with participation difficulty in 7 out of 9 community-based activities. 
Age. Prior studies involving school-aged children with and without disabilities suggest that participation patterns may differ depending on a child's age (Coster et al., 2013; Dunn \& Gardner, 2013; Jarus, Anaby, Bart, Engel-Yeger, \& Law, 2010; King et al., 2009; Law et al., 2004; Ullenhad et al., 2014). For example, Jarus and colleagues (2010) found that children without disabilities between 12 and 18 years old participated less intensely and diversely and with less enjoyment in after-school activities as compared to children ages 5 to 11 years old without disabilities. Similarly, cross-sectional and longitudinal studies with children ages 6 to 17 years old with and without disabilities suggest that children participate in activities less frequently over time (Coster et al., 2013; King et al., 2009; Law et al., 2006).

In contrast, there is mixed evidence about the impact of age on participation for children who are less than 6 years old. Dunst and colleagues (2002) found that the percentages of children who participate in family and community activities increases as children's age increases. However, this trend has not been clearly shown in recent psychometric testing of newly developed young children's participation measures, such as the CPQ (Rosenberg et al., 2010a), APCP (Law et al., 2012b), and YC-PEM (Khetani, Graham, Davies, Law, \& Simeonsson, 2015). For example, when examining participation in young children (0 to 5 years old) using the YCPEM, Khetani and colleagues (2015) found no clear age-related trends in home, daycare/preschool, or community participation, nor did they find age-related trends in perceived environmental support for participation in each setting.

Household income. Children's participation patterns have also been examined according to a family's collective household income, whereby lower income positively correlates with lower levels of children's participation, particularly in community activities (Anaby et al., 2014; Khetani et al., 2013c; Khetani et al., 2013d; Soref et al., 2011). For example, utilizing the PEM- 
CY, Khetani and colleagues (2014) found that caregivers residing in small communities and earning less than $\$ 80,000$ per year reported that their school-aged child participates less frequently, are less involved, and experience more environmental barriers (e.g., attitudes, physical structures) when participating in community activities.

However, the impact of household income on young children's participation is mixed (Khetani et al., 2013c; Law et al., 2012b; Rosenberg et al., \& 2010a). One study reported that caregivers earning less than $\$ 25,000$ annually were more likely to report community participation difficulty in 7 out of 9 activities (Khetani et al., 2013c). Another study involving young children 4-6 years old used the CPQ and found that income had a significant association on objective dimensions such as participation diversity (i.e., the number of activities), participation intensity (i.e., the frequency of participation), and independence level with participation, but not on subjective dimensions such as caregiver satisfaction and enjoyment (Rosenberg et al., 2010a). These data suggest that a clear trend between income and young children's participation has yet to be identified.

Overall, knowledge of participation patterns according to disability status, age, and household income can assist researchers and clinicians in identifying those clients who may benefit from interventions to improve participation-level outcomes. However, knowledge about discrepancies in participation does not inform decisions about how to focus an intervention to improve participation in a select activity or setting. Hence, prior studies have also applied newly developed measures to examine the associations of factors related to participation-level outcomes, such as environmental factors, because a more ecological model is necessary to address how child, family, and environmental factors impact participation level outcomes. 


\section{Correlates of Children's Participation}

Child, family, and environmental characteristics are three prominent factors that seem to impact a child's participation in activities (Anaby et al., 2014; Bedell et al., 2011; King et al., 2009; Soref et al., 2011). King and colleagues (2003) proposed one of the first models depicting these three factors and their hypothesized influence on out-of-school participation of children with disabilities (see Figure 1).

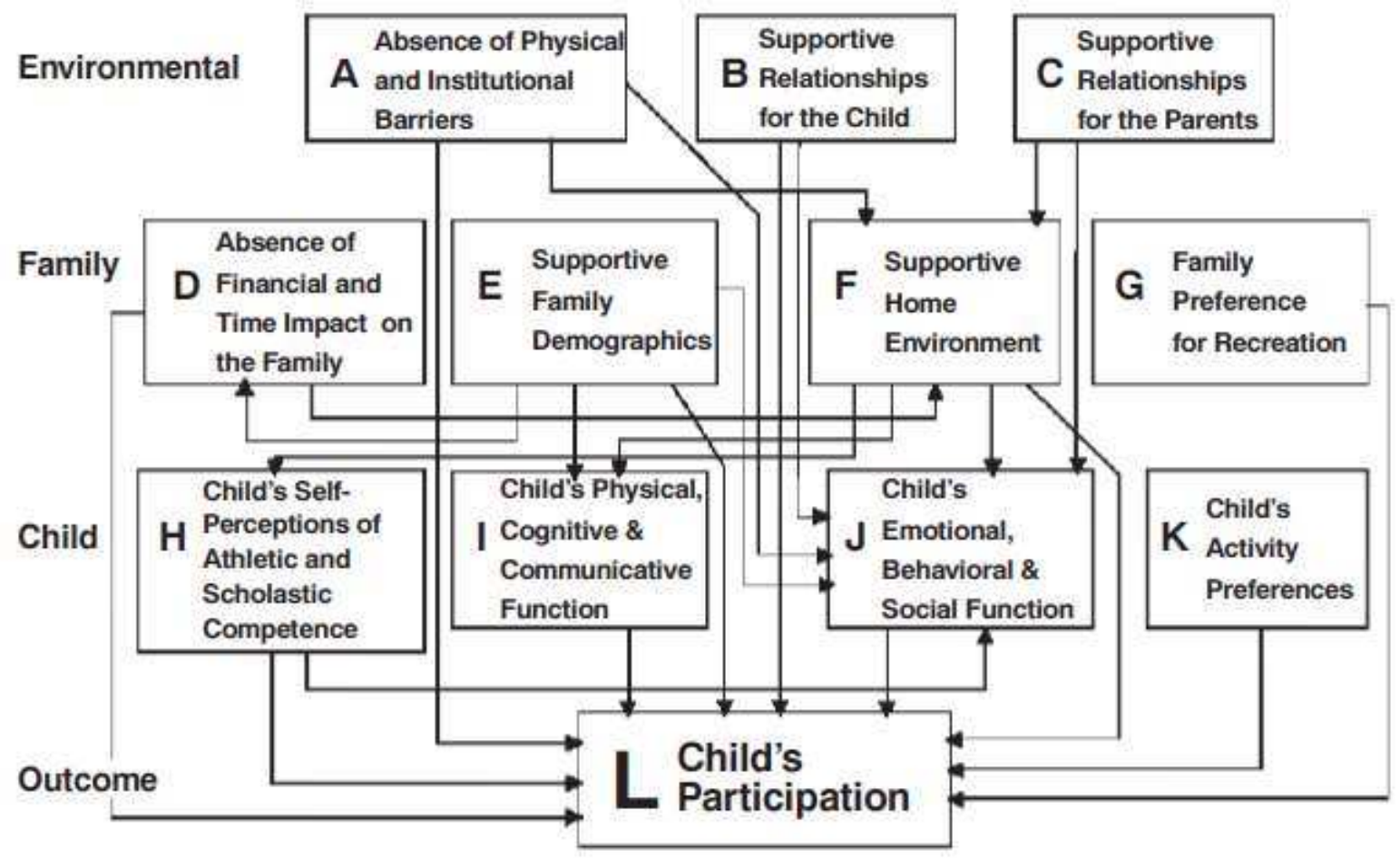

Figure 1 .

Note: Adapted from "A conceptual model of the factors affecting the recreation and leisure participation of children with disabilities" by King, G. et al., 2003, Physical and Occupational Therapy in Pediatrics, 23(1), p. 72.

The letters within the figure indicate different causal pathways through which these factors can exert influence on children's participation (King et al., 2003). Literature has continued to examine and build knowledge on the influences and associations of these three factors on participation. 
Child factors. Child factors include variables that are intrinsic to the child, such as age, gender, race/ethnicity, functional abilities, disability status, and preferences (King et al., 2003). As previously discussed, the child's age (Dunn \& Gardner, 2013; Jarus et al., 2010), functional abilities (Anaby et al., 2014; Dunn \& Gardner, 2013; Orlin et al., 2010), and disability status (Jarus et al., 2011; Law et al., 2012a) are factors that have been most commonly associated with participation difficulty. The child's age and functional abilities have also been found to be significant correlates of participation for children with disabilities (Colver et al., 2012; King et al., 2003; 2006; 2009). More specifically, a study using the SFA found that severity of impairment, as compared to type of impairment (e.g., physical or cognitive), was a significant predictor of children's participation in school-based activities (Mancini, Coster, Trombly, \& Heeren, 2000). Another study utilized the Pediatric Evaluation of Disability Inventory Computer Adaptive Test (PEDI-CAT: Haley, Coster, Ludlow, Kaltiwanger, \& Andrellow, 1992) in combination with the YC-PEM and found significant positive associations between young children's performance levels and their level of involvement in activities across the home, school, and community settings (Khetani et al., 2015).

Family factors. Family factors are variables associated with the immediate family and may include income, maternal and/or paternal education, primary language, and family activity preferences (King et al., 2003). Prior studies have found that family income has a significant effect on a child's participation (Anaby et al., 2014; Khetani et al., 2013a; Soref et al., 2011). For example, King and colleagues (2009) found that higher household income predicted less decline in recreational and social participation over a 3-year period. In addition, prior studies show that lower levels of maternal education have a negative effect on children's participation (Engel- 
Yeger \& Hamed-Daher, 2013; Hofferth \& Sandberg, 2001). This may suggest that maternal education could be a factor that identifies associations in children's participation.

Environmental factors. Relative to child and family factors, there is a lack of comprehensive literature on the predictive and associative properties of environmental supports and barriers on participation. King and colleagues (2009) reported that less supportive physical environments better predict a child's participation in recreational activities as opposed to predicting participation in physical activities. Colver and colleagues (2012) also found that, for children with cerebral palsy, the environment accounted for $14 \%$ to $52 \%$ of the variation in participation. Furthermore, limited social supports have also been shown to correlate with lower levels of participation (Anaby et al., 2013; Khetani et al., 2012b; Law et al., 2007). For example, one study found that for children with cerebral palsy, social support and attitudes in the home were the strongest independent correlates of their participation in recreation and responsibility activities (Colver et al., 2012). While these initial studies involved children with physical disabilities, Anaby and colleagues (2014) utilized a sample that was diverse according to disability type and status to identify the effect of environmental factors on participation outcomes. They found that environmental barriers had a direct effect on the levels of frequency and involvement for children and youth's participation in the home, school, and community settings (Anaby et al., 2014). However, a limitation to this study is that it is restricted to a full sample (i.e., children with and without disability grouped together), and does not address subjective dimensions of participation (i.e., caregiver satisfaction, child/family preferences).

In order to build clinically relevant knowledge about correlates of participation, future studies should: 1) incorporate diverse samples according to disability, 2) include younger children less than 6 years old, 3) address the subjective dimensions of participation, 4) provide 
setting specific knowledge, and 5) include specific environmental factors when examining correlates of participation. This type of knowledge may help providers to identify modifiable targets for intervention in a specific setting or activity if a caregiver desires change.

\section{Participation and Environment Measurement (PEM) Approach}

The PEM assessment approach may help to fill clinically relevant gaps in our knowledge about correlates of children's participation. The PEM approach is designed to enable researchers to feasibly obtain a multidimensional profile of a child's participation in activities that take place in home, school, and community settings, as well as information about environmental influences on children's participation for each of these three settings. To date, two caregiver questionnaires have been developed using the PEM measurement model: 1) the Participation and Environment Measure for Children and Youth (PEM-CY) (Coster et al., 2010) and 2) the Young Children's Participation and Environment Measure (YC-PEM) (Khetani et al., 2013b). Both questionnaires were designed with input from caregivers of children with a broad range of disabilities (e.g., psychosocial, learning, developmental) as well as caregivers of children without disabilities (Bedell et al., 2011; Khetani et al., 2013a). The PEM questionnaires were then each validated on a diverse sample according to the child's disability status and age, as well as the family's geographic location (Bedell et al., 2013; Coster et al., 2013; Khetani et al., 2013d; Khetani et al., 2015; Khetani, 2015; Law et al., 2012a).

Studies utilizing the PEM-CY have reported on disparities in both objective and subjective dimensions of participation across all three settings (Bedell et al., 2013; Coster et al., 2013; Law et al., 2012a). Specifically, children with disabilities have been found to engage in activities less frequently and be less involved, and caregivers of children with disabilities are more likely to desire change in their child's participation in school and community-based 
activities as compared to caregivers of children without disabilities, even after controlling for covariates such as age and family income (Bedell et al., 2013; Coster et al., 2013). While Law and colleagues (2012a) found no significant disability group differences in children's frequency and involvement in home-based activities, a higher percentage of caregivers of children with disabilities still wanted their child's participation to change for 8 out of 10 home activities (Law et al., 2012a). Anaby and colleagues (2014) then used the PEM-CY to examine child, family, and environmental factors as correlates of home participation (see Figure 2).

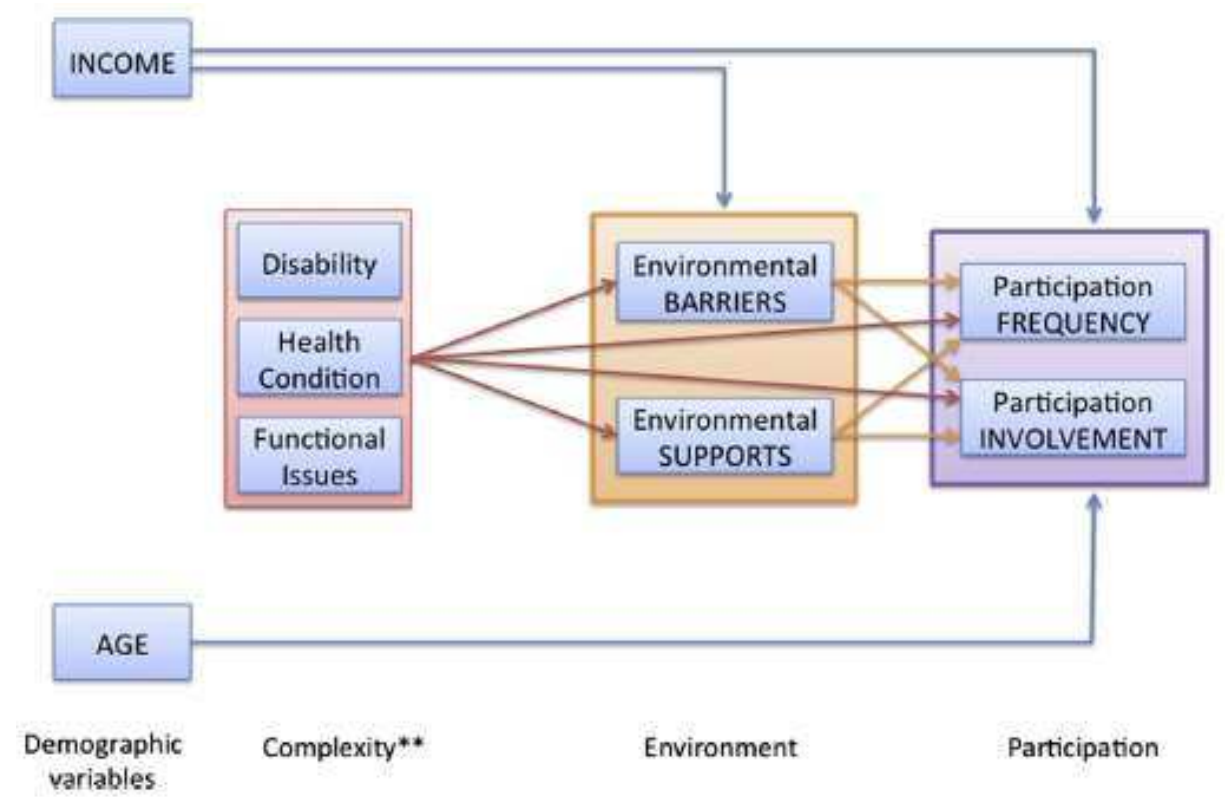

\section{Figure 2.}

Note: Adapted from "The mediating role of the environment in explaining participation of children and youth with and without disabilities across home, school, and community" by Anaby, D. et al., 2014, Archives of Physical Medicine and Rehabilitation, 95, 908-917.

They found that most of the variance in home participation frequency and involvement was explained by the child's age, functional issues, number of health conditions, family income, and environmental barriers (Anaby et al., 2014). Another study using this same dataset is underway to investigate correlates of caregiver satisfaction with children's participation in structured and 
unstructured activities in the school and community. Thus, it is not yet clear whether these same factors will show correlations with caregivers' satisfaction with participation in these settings.

The YC-PEM recently underwent psychometric validation. Significant disability group differences in participation frequency, level of involvement, and caregiver satisfaction were found in the daycare/preschool setting (Khetani et al., 2015). That is, a significantly higher percentage of caregivers raising young children with developmental disabilities and delays wanted their young child's participation to change with respect to daycare/preschool activities (Benjamin et al., 2016; Khetani et al., 2015). Caregivers of young children with disabilities and delays were also reported to have less environmental support for participation across all three settings when compared to young children without disabilities and delays (Benjamin et al., 2016; Khetani et al., 2015).

\section{Purpose}

Item-level analyses can help to identify both activities that are perceived to be problematic within a single setting and the type(s) of change most commonly desired across activities within a single setting. Studies examining correlates of caregiver satisfaction with their young children's participation will also be critical to building knowledge about the child, family, and environmental factors that are more or less likely to impact problems in young children's participation. In addition, the home is an ideal setting to begin examining correlates of caregiver satisfaction with young children's participation, because it is a setting in which young children

spend a majority of their time (Hofferth \& Sandberg, 2001) and where interventions involving young children often take place (Hebbeler et al., 2007). 
To our knowledge, this is the first study to examine patterns and correlates of caregiver satisfaction with young children's participation in home-based activities by addressing the following three aims:

1. To identify home activities in which caregivers of young children with and without disabilities and delays most often desire change.

Hypothesis 1a. Based on prior literature with school-aged children, caregivers of young children with and without disabilities will most often desire change in their young child's basic care routines and household chores (i.e., non-discretionary activities) (Law et al., 2012a).

Hypothesis 1b. Based on recent data collection with the YC-PEM, caregivers of young children with a disability or delay will more commonly want their child's participation to change in non-discretionary activities as compared to discretionary activities.

2. To examine the type(s) of change desired among caregivers of young children with and without disabilities and delays in home activities.

Hypothesis 2a. Based on recent data collection with the YC-PEM, caregivers of young children with developmental disabilities and delays will want their young child to be more helpful when participating in home activities as compared to caregivers of children without disabilities.

Hypothesis $2 \mathrm{~b}$. Based on recent data collection with the YC-PEM, caregivers of young children without disabilities and delays will want their young child to participate more frequently in home activities.

3. To identify associations among select child, family, and environmental factors and 
caregiver dissatisfaction with a young child's participation in home activities considering caregivers of young children with and without disabilities.

Hypothesis 3a. Child factors: The presence of a disability or delay will correlate with more caregiver dissatisfaction with their child's participation (Khetani et al., 2013;

Mancini et al., 2000; Orlin et al., 2010; Soref et al., 2011; Rosenberg et al., 2012)

Hypothesis 3b. Family factors: Lower household income will correlate with more caregiver dissatisfaction (Anaby et al., 2014; Khetani et al., 2013c; Soref et al., 2011); Hypothesis 3c. Environmental factors: Lower environmental support will correlate with more caregiver dissatisfaction in home-based activities (Khetani et al., 2015).

\section{Relevance of Thesis to Occupation and Rehabilitation Science (ORS)}

As a student pursuing the Master of Science degree option in the Department of Occupational Therapy at Colorado State University, my research contributes to the goal of occupational therapy (OT), which is to promote human performance and participation in everyday life. Both occupation science (OS) and rehabilitation science (RS) contribute to the knowledge base of the OT profession. Therefore, they each inform the design of this study, as well as the interpretation of study results. However, given the variable publication practices of occupational therapy researchers it is difficult to accurately classify the literature as either RS or OS. Leveraging my course-based learning, I will attempt to parse out the influence of both of these disciplines within my thesis.

My thesis focuses on using the YC-PEM to understand caregiver's satisfaction in their young child's participation in the home setting. When gathering background information on my thesis topic, the majority of the participation literature that I reviewed in the realm of children's participation measurement development had been published in RS journals with some influences 
from OS. Advances in measure development in the discipline of RS have been critical to gathering new information to build new knowledge about trends in children's participation. In addition, a majority of literature on context-specific trends in children's participation and relevant factors associated with participation outcomes has been published in traditionally RS journals. However, both RS and OS literature have been critical in gathering background information on the historical development and operationalization of children's participation.

Published studies in both RS and OS journals have informed the design of this study in terms of the focus on the subjective experience of participation in occupations. For example, OS literature emphasizes the importance of understanding subjective experiences of meaning relative to participation. Specifically, OS literature argues that participation can only be fully understood with both objective and subjective information. In contrast, RS literature has focused on including questions within assessments that gather subjective outcomes data. Some of the prior modeling studies in RS journals have also informed my hypotheses around group differences in caregiver dissatisfaction with young children's home participation and relevant correlates specific to the home setting.

Additionally, both RS and OS literature have informed my interpretation of study results. RS literature informed my discussion concerning the impact of a child's disability status on participation outcomes and in analyzing environmental influence on children's participation. OS has more strongly emphasized subjective outcomes as compared to the discipline of RS. Hence, I drew on some of the descriptive OS literature to discuss my key findings specific to those home activities, in which caregivers are dissatisfied with their young child's participation. Considering caregiver dissatisfaction, OS literature also provides evidence regarding caregivers' subjective experiences in order to inform clinical practice, such as goal and intervention planning. In my 
discussion, I suggest that future research in OS and RS should consider examining how factors relate differently to subjective and objective aspects of participation. 


\section{Methods}

\section{Study Design}

This study employed a cross-sectional design to address the main study aims. Classen (2006) suggests that cross-sectional studies typically examine the relationship between a health outcome and relevant variables. For this study, I examined the home activities in which caregivers most desire change and the specific type(s) of change desired. I also examined the association between child, family, and environmental factors on the outcome of caregiver's desire for change in their young children's home participation (see Appendix B for a complete variable map).

\section{Participants}

Participants were 395 caregivers of young children who enrolled in a psychometric evaluation of the YC-PEM (June-October 2013). The research team employed convenience and snowball sampling methods to recruit study participants. Initially, program directors of early intervention agencies and early childhood centers in the Colorado Front Range and Wyoming communities were contacted and provided with recruitment flyers in order to distribute information to families. Information about the study was also sent to families through agencysponsored newsletters and social media websites. Researchers also attended community events to recruit and enroll families, before expanding recruitment to other related and established contacts (e.g., early intervention programs, summer camps, medical clinics) within the United States and Canada. Researchers also mailed flyers to participants to share with their family members, friends, and colleagues. The following inclusion criteria were used to determine eligibility: 1) speaks, reads, and writes in English, 2) resides in the United States or Canada, 3) is a parent or 
legal guardian 18 years or older, 4) has a child between the ages of 0 and 5 years, and 5) has internet access.

\section{Measures}

Demographic questionnaire. Caregivers provided information on child factors (e.g., disability status, age, gender) and family factors (e.g., caregiver education level, employment status, income). Data on children's service utilization were gathered by asking caregivers whether or not their child receives speech and language therapy, occupational therapy, physical therapy, medical or private specialized preschool program services, public special education preschool services, or other therapies/services. If caregivers indicated "yes", then they were also asked for how long their child has been receiving this service and for how many hours per week. If caregivers reported that their child receives early intervention or early childhood special education services, caregivers were also asked to specify whether the child was deemed eligible for services due to diagnosis, developmental delay (no diagnosis), or at risk for delay. For main analyses, a "delay" subgroup (n=93) represented all children receiving EI or ECSE services, whereas children were otherwise assigned to the "no delay" subgroup $(n=302)$.

\section{Pediatric Evaluation of Disability Inventory Computer Adaptive Test (PEDI-CAT).}

The PEDI-CAT (Haley et al., 1992) is a caregiver report assessment that gathers data on functional task performance for children up to 18 years old. Normative scores are generated for 4 domains of the assessment: daily activities (68 items), mobility (97 items), social/cognitive (60 items), and responsibility (51 items) (Haley et al, 2011). PEDI-CAT domains have excellent testretest reliability, with intraclass correlation coefficients ranging from 0.96 to 0.99 (Dumas et al., 2012). Khetani and colleagues (2015) found small to moderate associations between three of four PEDI-CAT normative scores and YC-PEM summary scores across settings. Therefore, PEDI- 
CAT normative scores for these three domains (daily activities, mobility, and social/cognitive) were used in Aim 3 (i.e., examining child, family, and environmental correlates of caregiver satisfaction) of this study.

Young Children's Participation and Environment Measure (YC-PEM). The YCPEM (Khetani et al., 2013b) is a questionnaire that assesses caregivers' perceptions of their young child's participation and environmental supports and barriers to participation. The YCPEM contains three sections: home, daycare/preschool, and community. We leveraged data from the YC-PEM home section to address the research questions for this study.

The YC-PEM home section has two parts. The first part asks caregivers to evaluate their child's participation in 13 types of home activities: 1) getting rest, 2) personal care management, 3) getting clean, 4) meal time, 5) cleaning up, 6) meal preparation, 7) taking care of other family members, 8) laundry and dishes, 9) arts, crafts, stories, and music, 10) screen time, 11) indoor play and games, 12) celebrations at home, and 13) house guests.

For each activity, caregivers assessed their child's participation in 3 dimensions: frequency (8-point scale, from never [0] to once of more each day [7]); level of involvement (5point scale, from not very involved [1] to very involved [5]) with caregivers skipping this step if they answered 'never' to the frequency question); and desire for change in the young child's participation (yes [1] or no [0]). If caregivers answered 'yes, desire change' they were asked to specify what type(s) of change they desired out of 5 options (do more often, do less often, be more interactive, be more helpful, and participate in a broader variety of activities) (see Appendix A for excerpt of the YC-PEM home participation section). Caregivers who desired change were then prompted to enter up to 3 strategies that the caregiver has used to promote the child's participation in activities of that type. For this study, only responses to the third 
dimension (desire for change) were used. For Aim 3 analyses, a YC-PEM home participation summary score was calculated by summing the number of YC-PEM home items scored as 'yes, change desired', dividing by the total number of items in the home setting $(n=13)$, and multiplied by 100 to get a percentage (range $=0-100 \%)$.

After completing the home participation section, caregivers completed the second part of the assessment which was to evaluate 13 environmental features (e.g., physical layout, cognitive demands of activities, attitudes of others) and resources (e.g., supplies, information, money) in terms of their impact on the young child's participation in the home setting. Participants were also provided with examples of environmental features and resources. Perceived impact of environmental features on participation was assessed on a 3-point scale (no impact/usually helps [3] to usually makes harder [1]), and perceived impact of environmental resources on participation was assessed on a 3-point scale (no impact/usually helps [3] to usually no [1]). For Aim 3 analyses, an environmental support summary score was calculated by summing all responses, dividing by the maximum possible score within the home setting (n=39), and multiplying by 100 . Before proceeding to the next YC-PEM section, participants were again prompted to describe up to three strategies for promoting their child's participation in the home.

All four YC-PEM scales in the home setting (i.e. frequency, level of involvement, desire change, and environmental support) have internal consistencies ranging from good to excellent (Khetani et al., 2015). Specific to the scales being used in this study, the YC-PEM home desire change scale had an internal consistency of 0.84 and the environmental support scale had an internal consistency of 0.96 . The test-retest reliability for caregiver desire for change at home was fair (0.57) and environmental support was excellent (0.91). Home environmental support 
summary scores were significantly different between caregivers of young children with a delay $(66.7 \%)$ versus no delay $(94.9 \%)$.

\section{Data Collection}

This study involves secondary analyses of data collected during the YC-PEM validation study (Khetani et al., 2015). Approval from the Institutional Review Board at Colorado State University was obtained prior to participant recruitment and data collection. In addition, a secure web-based platform was used for data collection and data management during the enrollment period (June-October 2013).

Each eligible participant enrolled in the study via a web link that was located on the study flyer. This web link led participants to an online platform. On the platform, participants were first asked to confirm their eligibility according the inclusion criteria and then create user accounts to gain secure access to the study site for online consent and survey completion. After accessing the study site, study participants first provided informed consent and completed a demographic questionnaire and YC-PEM online (completion time: 45-50 minutes). Participants were then given the option of providing their contact information and availability to complete the PEDI-CAT via telephone interview (completion time: 15-20 minutes). Each participant received a \$10 US cash or gift card mailed payment for participating in this study. 


\section{Data Analysis}

Data were initially collected during a psychometric validation of YC-PEM (June-October 2013) and sent to a central data repository. Following data collection, these data were exported as a Microsoft Excel file and imported into SPSS 22.0 (IBM, 2013) for analyses. For this study, participant responses to select items on the demographic questionnaire, YC-PEM home section, and PEDI-CAT were extracted from the main YC-PEM validation study dataset and stored in a separate SPSS 23.00 (IBM, 2014) dataset for analyses.

\section{Preliminary Analyses}

Normality. Data were first screened via visual inspection (histograms) and normality statistics (absolute values of $>2$ for skewness and $>7$ for kurtosis) to ensure that the assumptions of normality were met for all study variables (Field, 2014). All 13 YC-PEM home participation (caregiver desire for change) items and all 13 home environmental items met assumptions of normality, affording for the use of parametric tests for analyses involving these items.

Examination of child (age, PEDI-CAT normative scores, disability status) and family (household income) variables also imply that assumptions of normality are met, supporting their inclusion without transformation in Aim 3 analyses.

Missing data. No YC-PEM home participation (caregiver desire for change) items contained random missing data; however, the home environmental items on the YC-PEM contained random missing data in $2.5 \%$ of cases across 13 environmental items and were retained with use of pairwise deletion (Osborne, 2013). Specifically, missing data in the 13 environmental items consisted of 1 missing value (0.12\%) for 6 items, 2 missing values $(0.08 \%)$ for 2 items, 4 missing values $(0.08 \%)$ for 1 item, 5 missing values $(0.29 \%)$ for 3 items, and 6 missing values $(0.12 \% \%) 1$ item. Most of these missing data are within the environmental 
resource items (e.g., supplies, information, time, and money). One participant had missing data on all 13 home environmental items, resulting in case deletion prior to running analyses for Aim 3. All other missing data for YC-PEM home environmental items were treated using mean substitution, whereby the overall sample mean for each environmental item was substituted for each corresponding participants' missing environmental data (Osborne, 2013). Mean substitution was selected because data were missing at random in less than $20 \%$ of cases (Enders, 2010; Osborne, 2013).

In contrast to YC-PEM data, there were 114 cases (29.1\%) with missing PEDI-CAT data. These missing data were considered missing not at random (MNAR) because the missing data is systematically related to the unseen observations (Baraldi \& Enders, 2010; Osborne, 2013). The recommended approach for handling MNAR data, multiple imputation, was pursued (Baraldi \& Enders, 2010; Enders, 2010; IBM, 2011; Osborne, 2013). The purpose of multiple imputation is to generate possible values for missing values based on existing data (i.e., participants with complete PEDI-CAT data; IBM, 2011). The suggested number of imputations to perform on missing data is 20 , and it is also recommended that the imputation is run on all independent variables in the dataset, not just the variables that are missing (Enders, 2010). Therefore, 20 imputations were performed on all child, family, and environment variables, which thus created 20 additional datasets to the original dataset. Upon running regression analyses, SPSS 23.0 (IBM, 2014) automatically pools together (i.e., averages) all 20 datasets to create regression results based on the "best fit" imputation. The imputed PEDI-CAT data were then used for Aim 3 analyses. No other child (i.e., age) or family (i.e., household income) factors contained missing data. 
Multicollinearity. To ensure that there were no violations of multicollinearity, which suggests redundancy in the data, inter-item correlations were run for pairs of select study variables using Pearson correlations. Inter-item Pearson correlations were first run to examine associations between 13 items on the YC-PEM home desire change scale. All correlations were found to be less than 0.587 , with most correlations being fair or poor, supporting inclusion of all YC-PEM home desire change items separately for Aim 1 and 2 item level group comparisons (Kielhofner, 2006).

Inter-item correlations were next run on select child, family, and environmental variables. Correlations between the three PEDI-CAT domain normative scores (e.g., mobility, daily activities, and social/cognitive) ranged from 0.642 and 0.748 , which indicates a moderate relationship. However, these domain scores were entered separately in Aim 3 analyses to afford for greater specificity when interpreting Aim 3 results pertaining to the relative effect of functional performance on caregiver satisfaction with a young child's home participation. Pearson correlations were less than 0.542 for all correlations between remaining child (age, disability status) variables, thus supporting the inclusion of all variables separately in analyses. Pearson correlations were also run on select family factors. The correlation between respondent education level and household income was statistically significant $(p<0.001, r=0.387)$, which signifies the need to select one of these variables for inclusion in Aim 3 analyses. The household income variable was selected due to its higher correlation with the outcome variable, caregiver desire change ( $p<0.05, r=0.095$ ). For environmental items, Cronbach's alpha for the 13 environmental items is 0.956 , which indicates that items could be collapsed to decrease variable count. Thus, an environmental support summary score will be used in Aim 3 analyses. 
As shown in Table 1, descriptive statistics were used to summarize the characteristics of the total sample, as well as the two subgroups based on the child's disability status (delay, no delay). Chi-square analyses were used in Table 1 in order to determine if the two subgroups differed on select demographic characteristics. Level of significance was set to $p<.05$.

\section{Main Analyses}

Aims 1 and 2. Descriptive statistics were first used to 1) identify common types of home activities in which caregivers are dissatisfied based on their reported desire for change (yes, no) (Aim 1) and 2) to examine common type(s) of change that caregivers most commonly desired for each home activity (Aim 2). Aim 1 and 2 analyses were conducted for the total sample and subgroups (delay, no delay). Chi-square analyses were then used for Aims 1 and 2 in order to examine item-level group differences in caregiver dissatisfaction (yes desire change vs. no desire change) with their child's participation across 13 home activities. We planned to control for group differences in respondent education level and child gender in cases where there were statistically significant item-level disability group differences. Due to multiple comparisons, Bonferroni corrections were made to reduce Type 1 error rate by dividing 0.05 by the number of comparison tests conducted for each set of group comparisons. This resulted in a significance level of .004 for item-level group comparisons.

Aim 3. Aim 3 analyses were pursued using the YC-PEM home desire change summary score because Aim 1 results did not suggest a clear cut-off in the types of home activities deemed most concerning to caregivers. For Aim 3 analyses, there was one outcome variable that is continuous (percent desire change in home activities) and two independent variables that are categorical (disability status, household income) and multiple continuous variables (child age, PEDI-CAT daily activities, mobility, and social/cognitive normative scores, environmental 
support), resulting in the decision to pursue multiple linear regression analyses (Field, 2014). Multiple linear regression was run on the total sample to examine the extent to which select child, family, and environmental factors (see Appendix B for variable map) explain the variance in caregiver desire for change in young children's home participation.

For the model, reported annual household income, which is a categorical variable, is included as a family factor. Since regression models that utilize categorical variables only account for one response category, dummy variables were created for household income categories (See Table 6; Henry, 2015). In addition, in order to increase power and confidence in regression results, some household income categories were collapsed due to small cell count $(<25 \%)$. Mean income was used to create two binary variables from the remaining income categories pertaining to household income $(\leq \$ 60,000, \geq \$ 60,001)$. Since the disability status variable is already binary (e.g., yes, receives services vs. no, does not receive services), dummy variables were not created.

The values of the residuals were examined via data output to ensure assumptions were met. Specifically, data output was examined to ensure a linear relationship between variables, that the variance of the residuals is constant (homoscedasticity), and that the values of the residuals are independent (independent errors rather than autocorrelation), and the values of the residuals are normally distributed.

Power calculations show that with 8 independent variables, such as in Aim 3, a multiple regression analysis would require a sample size of at least $\mathrm{N}=89$ in order to be $\sim 95 \%$ confident in the results from the regression analysis (Buchner, Erdfelder, Faul, \& Lang, 2013) 


\section{Results}

\section{Participant Characteristics}

Participants included 395 caregivers of children between the ages of 1 and 71 months who participated in the initial online validation of the YC-PEM questionnaire. Most respondents self-identified as mothers or female legal guardians (95.9\%), married (90.1\%), and held at least a college degree $(79.3 \%)$. At least half of the participants were employed outside the home (50.6\%) and reported an annual household income of $\$ 60,000$ or greater $(63.5 \%)$.

A majority of the young children were Caucasian (81.0\%), over half were male $(56.2 \%)$, and they had a mean age of 36.5 months $(S D=20.1)$. Additionally, over half $(50.9 \%)$ of participants reported that their child attended some sort of childcare program during the day. Also, while there were fewer children with a delay $(n=93)$ as compared to children without a delay $(n=302)$, both groups of children (delay or no delay) were similar in a majority of sociodemographic characteristics. However, statistically significant differences were found in two participant characteristics, as there were significantly more boys in the subsample of children with delays and lower levels of education amongst caregivers of children with delays.

Nearly one fourth $(23.5 \%)$ of the young children sampled received services (e.g., medical, therapeutic, special education) to address a wide range of functional problems. Speech therapy was the most commonly received service $(75.3 \%)$, followed by occupational therapy services (58.9\%), and other therapy/services (33.3\%). More than half of caregivers of children with a delay reported functional problems for 8 out of 12 areas assessed. The most commonly reported functional problems included managing emotions, managing behavior, and paying attention. Approximately 1 in every 5 respondents $(22.5 \%)$ indicated that their child was qualified to receive services due to high risk for delay, developmental delay, or a diagnosed 
condition. Table 1 shows complete demographic characteristics for the total sample and subsamples according the presence or absence of a delay per caregiver report, while Table 2 displays characteristics specific to the delay group.

Table 1

Family and Child Characteristics

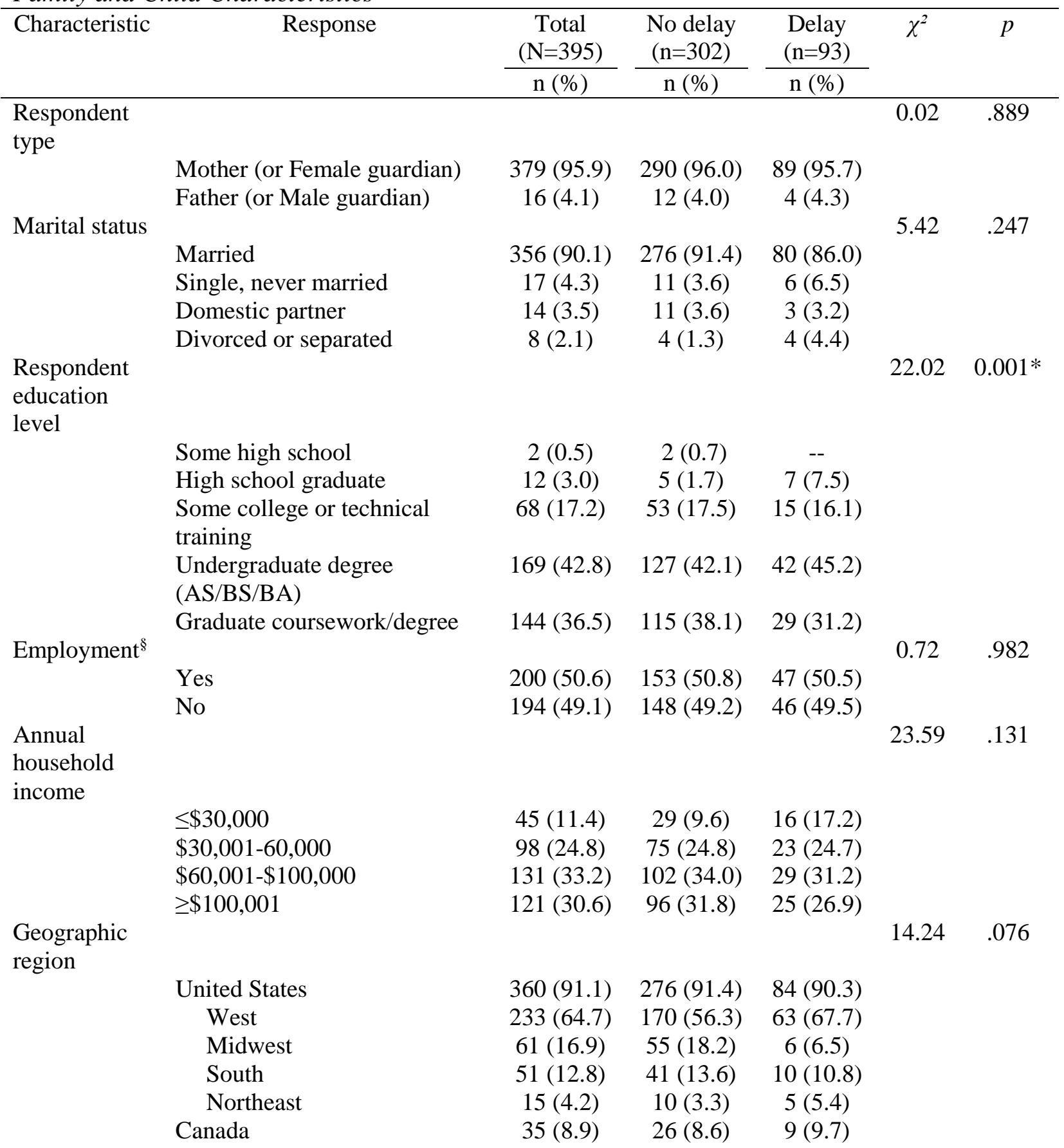


Childcare

$7.67 \quad .053$

arrangement ${ }^{\text {tI }}$

Child age

Parent or legal guardian

$\begin{array}{ccc}322(81.5) & 251(83.1) & 71(76.3) \\ 131(33.2) & 94(31.1) & 37(39.8) \\ 31(7.9) & 25(8.3) & 6(6.5) \\ & & \\ 22(5.5) & 15(5.0) & 7(7.5) \\ 17(4.3) & 9(3.0) & 8(8.6)\end{array}$

(months)

Daycare/pre-k/kindergarten

Family daycare/cooperative nursery

In-home provider

Other

$17(4.3)$

$9(3.0) \quad 8(8.6)$

$72.37 \quad .336$

$60(15.2) \quad 52(17.2) \quad 8(8.6)$

$64(16.2) \quad 51(16.9) \quad 13(14.0)$

$81(20.5) \quad 60(19.9) \quad 21(22.6)$

$51(12.9) \quad 36(11.9) \quad 15(16.1)$

$77(19.5) \quad 58(19.2) \quad 19(20.4)$

$62(15.7) \quad 45(14.9) \quad 17(18.3)$

Child gender

Male

Female

$222(56.2) \quad 159(52.6) \quad 63(67.7)$

$173(43.8) \quad 143(47.4) \quad 30(32.3)$

Child race ${ }^{\S}$

American Indian/Alaskan
Native
Asian
Black or African American
White
Multiracial
Other

$1(0.3) \quad 1(0.3) \quad--$

$7(1.8) \quad 5(1.7) \quad 2(2.2)$

$4(1.0) \quad 3(1.0) \quad 1(1.1)$

$320(81.0) \quad 243(80.7) \quad 77(82.8)$

$49(12.4) \quad 40(13.3) \quad 9(9.7)$

$6.58 \quad .010^{*}$

$2.13 \quad .907$

$12(3.0) \quad 8(2.7) \quad 4(4.3)$

\footnotetext{
II Participants could select multiple responses

${ }^{\S}$ Missing data

$* p<.05$
}

Table 2

\begin{tabular}{lc} 
Functional Characteristics and Service Use Patterns for Children with Delays \\
\hline Characteristic & Delay \\
& $(\mathrm{n}=93)$ \\
$\mathrm{n}(\%)$
\end{tabular}

Disability status ${ }^{\S}$

Functional problems ${ }^{\text {II }}$

$\begin{array}{lc}\text { At risk for developmental delay } & 6(6.7) \\ \text { Developmental delay (no diagnosis) } & 31(34.8) \\ \text { Diagnosis } & 52(58.4)\end{array}$

$\begin{array}{ll}\text { Mobility } & 47(50.5) \\ \text { Processing information } & 54(58.1) \\ \text { Seeing } & 27(29.0) \\ \text { Hearing } & 17(18.3) \\ \text { Communicating with others } & 69(74.2) \\ \text { Self-feeding } & 41(44.1) \\ \text { Bladder and bowel control } & 39(42.0) \\ \text { Paying attention } & 54(58.1)\end{array}$


Safety awareness

Controlling behavior

Managing emotions

Reacting to sensations

Service utilization ${ }^{\mathbb{} \S}$

Speech and language therapy

Occupational therapy

Physical therapy

Medical/specialized preschool

Public special education preschool

Other therapy/services
$54(58.1)$

$57(61.3)$

$54(58.1)$

$53(57.0)$

$70(75.3)$

$53(58.9)$

$25(27.5)$

$4(4.5)$

$14(16.3)$

$29(33.3)$

"Participants could select multiple responses

${ }^{\S}$ Missing data

Aim 1: Areas of Caregiver Dissatisfaction with Young Children's Home Participation

Caregivers most often expressed concern with their young child's participation in cleaning up activities at home (e.g., picking up toys). At least half of the total sample also desired change in their young child's participation in personal care management (e.g., dressing) and getting clean (e.g., bathing). Caregivers least often expressed concern with respect to their child taking care of others, entertaining houseguests, and taking part in celebrations at home.

As shown in Table 3 below, no statistically significant item-level group differences were found in caregiver dissatisfaction based on the child's disability status. However, visual inspection of these data reveals a trend towards small percent differences in the satisfaction of caregivers of children with and without delays by activity type. A higher percentage of caregivers of young children with delays desired change across all non-discretionary home activities (i.e., activities seen as essential to sustaining daily life and a household; not optional activities), including all 4 basic care routines (e.g., personal care, mealtime, getting clean, and getting rest) and 3 out of 4 household chores (e.g., cleaning up, meal preparation, laundry and dishes), when compared to caregivers of young children without delays. Similarly, a higher percentage of caregivers of young children with delays desired change in discretionary activities like socializing with friends and family members (e.g., house guests, celebrations at home). In 
contrast, a higher percentage of caregivers of children without delays desired their young child's participation to change in discretionary activities such as interactive and organized play (e.g., screen time and indoor play and games) when compared to caregivers of young children with delays.

Table 3

Caregivers Desire for Change in their Young Child's Participation in Home Activities

\begin{tabular}{|c|c|c|c|c|c|}
\hline & $\begin{array}{c}\text { Total } \\
\mathrm{N}=395\end{array}$ & $\begin{array}{c}\text { No Delay } \\
\mathrm{n}=302\end{array}$ & $\begin{array}{l}\begin{array}{l}\text { Delay } \\
\mathrm{n}=93\end{array} \\
\mathrm{n}(\%)\end{array}$ & $\chi^{2}$ & $p$ \\
\hline 1. Cleaning up & $254(64.3)$ & $191(63.2)$ & $63(67.7)$ & .626 & .429 \\
\hline 2. Personal care & $212(53.7)$ & $158(52.3)$ & $54(58.1)$ & .944 & .331 \\
\hline 3. Getting clean & $198(50.1)$ & $150(49.7)$ & $48(51.6)$ & .107 & .743 \\
\hline 4. Mealtime & $197(49.9)$ & $146(48.3)$ & $51(54.8)$ & 1.200 & .273 \\
\hline 5. Indoor play and games & $177(44.8)$ & $140(46.4)$ & $37(39.8)$ & 1.242 & .265 \\
\hline 5. Screen time & $177(44.8)$ & $140(46.4)$ & $37(39.8)$ & 1.242 & .265 \\
\hline 6. Meal preparation & $171(43.3)$ & $131(43.0)$ & $40(43.4)$ & .004 & .950 \\
\hline 7. Laundry and dishes & $155(39.2)$ & $114(37.7)$ & $41(44.1)$ & 1.198 & .274 \\
\hline 8. Getting rest & $153(38.7)$ & $115(38.1)$ & $38(40.9)$ & .232 & .630 \\
\hline 9. Arts, crafts, music, and stories & $110(27.8)$ & $83(27.5)$ & $27(29.0)$ & .085 & .771 \\
\hline 10. Taking care of others & $98(24.8)$ & $79(26.2)$ & $19(20.4)$ & 1.251 & .263 \\
\hline 11. House guests & $94(23.8)$ & $69(22.8)$ & $25(26.9)$ & .638 & .424 \\
\hline 12. Celebrations at home & $83(21.0)$ & $59(19.5)$ & $24(25.8)$ & 1.684 & .194 \\
\hline
\end{tabular}

\section{Aim 2: Type(s) of Caregiver Change Desired with Young Children's Home Participation}

As summarized in Table 4 below, no statistically significant disability group differences were identified in type(s) of caregiver change desired. However, some trends in type(s) of caregiver change desired according to activity type were observed. Among caregivers reporting dissatisfaction, caregivers commonly expressed concerns with their young child's level of involvement (i.e., 'be more helpful' and 'be more interactive') in home activities. Specifically, a higher percentage of caregivers in both groups expressed a desire for their child to 'be more helpful', as compared to 'be more interactive', across all 4 basic care routines (i.e., personal care, getting clean, mealtime, getting rest) and 3 of 4 household chores (i.e., cleaning up, meal preparation, and laundry and dishes). In contrast, a higher percentage of caregivers in both 
groups expressed different types of change with respect to their young child's participation in discretionary home activities (i.e., activities done for enjoyment and well-being; optional activities): 1) 'do less often' for 2 out of 3 interactive and organized play activities (i.e., screen time, indoor play and games) and 2) 'be more interactive' in activities that involve socializing with friends and family (i.e., house guests, celebrations at home). Caregivers were least often concerned with their child participating in a broader variety of home activities. While there were no statistically significant group differences, personal care and getting rest activities were trending towards statistical significance.

Table 4

Type(s) of Change Desired in Problematic Home Activities ${ }^{\text {It }}$

\begin{tabular}{|c|c|c|c|c|c|}
\hline & $\begin{array}{c}\text { Total } \\
\mathrm{N}=395\end{array}$ & $\begin{array}{c}\text { No Delay } \\
\mathrm{n}=302\end{array}$ & $\begin{array}{l}\begin{array}{l}\text { Delay } \\
\mathrm{n}=93\end{array} \\
\mathrm{n}(\%)\end{array}$ & $\chi^{2}$ & $p$ \\
\hline Cleaning up & $254(64.3)$ & $191(63.2)$ & $63(67.7)$ & & \\
\hline Frequency & $118(29.9)$ & $91(30.2)$ & $27(29.0)$ & 0.041 & 0.839 \\
\hline Do more often & $116(29.4)$ & $89(29.5)$ & $27(29.0)$ & & \\
\hline Do less often & $2(0.5)$ & $2(0.7)$ & $0(0.0)$ & & \\
\hline Involvement & $208(52.7)$ & $157(52.0)$ & $51(54.8)$ & 1.732 & 0.421 \\
\hline Be more helpful & $156(39.5)$ & $116(38.4)$ & $40(43.0)$ & & \\
\hline Be more interactive & $52(13.2)$ & $41(13.6)$ & $11(11.8)$ & & \\
\hline Broader variety of activities & $47(11.9)$ & $38(12.6)$ & $9(9.7)$ & 0.573 & 0.449 \\
\hline Personal care & $212(53.7)$ & $158(52.3)$ & $54(58.1)$ & & \\
\hline Frequency & $54(13.7)$ & $47(15.6)$ & $7(7.6)$ & 3.891 & 0.049 \\
\hline Do more often & $53(13.4)$ & 47 (15.6) & $6(6.5)$ & & \\
\hline Do less often & $1(0.3)$ & $0(0.0)$ & $1(1.1)$ & & \\
\hline Involvement & $188(47.6)$ & $137(45.4)$ & $51(54.9)$ & 3.115 & 0.211 \\
\hline Be more helpful & $123(31.1)$ & 89 (29.5) & 34 (36.6) & & \\
\hline Be more interactive & $65(16.5)$ & $48(15.9)$ & $17(18.3)$ & & \\
\hline Broader variety of activities & $45(11.4)$ & $36(11.9)$ & $9(9.7)$ & 0.354 & 0.552 \\
\hline Getting clean & $198(50.1)$ & $150(49.7)$ & $48(51.6)$ & & \\
\hline Frequency & $64(16.2)$ & $53(17.5)$ & $11(11.8)$ & 1.714 & 0.190 \\
\hline Do more often & $63(15.9)$ & $52(17.2)$ & $11(11.8)$ & & \\
\hline Do less often & $1(0.3)$ & $1(0.3)$ & $0(0.0)$ & & \\
\hline Involvement & $159(40.3)$ & $122(40.7)$ & $37(39.8)$ & 3.841 & 0.147 \\
\hline Be more helpful & $103(26.1)$ & $76(25.5)$ & $27(29.0)$ & & \\
\hline Be more interactive & $56(14.2)$ & $46(15.2)$ & $10(10.8)$ & & \\
\hline Broader variety of activities & $35(8.9)$ & $27(8.9)$ & $8(8.6)$ & 0.010 & 0.920 \\
\hline Mealtime & $197(49.9)$ & $146(48.3)$ & $51(54.8)$ & & \\
\hline Frequency & $48(12.1)$ & $38(12.6)$ & $10(10.8)$ & 0.223 & 0.637 \\
\hline Do more often & $46(11.6)$ & $36(11.9)$ & $10(10.8)$ & & \\
\hline
\end{tabular}




\begin{tabular}{|c|c|c|c|c|c|}
\hline Do less often & $2(0.5)$ & $2(0.7)$ & $0(0.0)$ & & \\
\hline Involvement & $165(41.8)$ & $124(41.1)$ & $41(44.1)$ & 2.841 & 0.242 \\
\hline Be more helpful & $98(24.8)$ & $79(26.2)$ & $19(20.4)$ & & \\
\hline Be more interactive & $67(17.0)$ & $45(14.9)$ & $22(23.7)$ & & \\
\hline Broader variety of activities & $59(14.9)$ & $46(15.2)$ & $13(14.0)$ & 0.088 & 0.767 \\
\hline Indoor play and games & $177(44.8)$ & $140(46.4)$ & $37(39.8)$ & & \\
\hline Frequency & $152(38.5)$ & $122(40.4)$ & $30(32.3)$ & 1.990 & 0.158 \\
\hline Do more often & $2(0.5)$ & $0(0.0)$ & $2(2.2)$ & & \\
\hline Do less often & $150(38.0)$ & $122(40.4)$ & $28(30.1)$ & & \\
\hline Involvement & $25(6.4)$ & $17(5.6)$ & $8(8.6)$ & 1.060 & 0.303 \\
\hline Be more helpful & $1(0.3)$ & $0(0.0)$ & $1(1.1)$ & & \\
\hline Be more interactive & $24(6.1)$ & $17(5.6)$ & $7(7.5)$ & & \\
\hline Broader variety of activities & $21(5.3)$ & $17(5.6)$ & $4(4.3)$ & 0.249 & 0.618 \\
\hline Screen time & $177(44.8)$ & $140(46.4)$ & $37(39.8)$ & & \\
\hline Frequency & $152(38.5)$ & $122(40.4)$ & $30(32.3)$ & 1.990 & 0.158 \\
\hline Do more often & $2(0.5)$ & $0(0.0)$ & $2(2.2)$ & & \\
\hline Do less often & $150(38.0)$ & $122(40.4)$ & $28(30.1)$ & & \\
\hline Involvement & $25(6.4)$ & $17(5.6)$ & $8(8.6)$ & 1.060 & 0.303 \\
\hline Be more helpful & $1(0.3)$ & $0(0.0)$ & $1(1.1)$ & & \\
\hline Be more interactive & $24(6.1)$ & $17(5.6)$ & $7(7.5)$ & & \\
\hline Broader variety of activities & $21(5.3)$ & $17(5.6)$ & $4(4.3)$ & 0.249 & 0.618 \\
\hline Meal preparation & $171(43.3)$ & $131(43.4)$ & $40(43.0)$ & & \\
\hline Frequency & $73(18.5)$ & $59(19.5)$ & $14(15.1)$ & 0.928 & 0.330 \\
\hline Do more often & $72(18.2)$ & $58(19.2)$ & $14(15.1)$ & & \\
\hline Do less often & $1(0.3)$ & $1(0.3)$ & $0(0.0)$ & & \\
\hline Involvement & $116(29.4)$ & $94(31.1)$ & $22(23.6)$ & 1.537 & 0.464 \\
\hline Be more helpful & $73(18.5)$ & $62(20.5)$ & $11(11.8)$ & & \\
\hline Be more interactive & $43(10.9)$ & $32(10.6)$ & $11(11.8)$ & & \\
\hline Broader variety of activities & $52(13.2)$ & $40(13.2)$ & $12(12.9)$ & 0.007 & 0.932 \\
\hline Laundry and dishes & $155(39.2)$ & $114(37.7)$ & $41(44.1)$ & & \\
\hline Frequency & $75(19.0)$ & $60(19.9)$ & $15(16.2)$ & 0.646 & 0.422 \\
\hline Do more often & $70(17.7)$ & $57(18.9)$ & $13(14.0)$ & & \\
\hline Do less often & $5(1.3)$ & $3(1.0)$ & $2(2.2)$ & & \\
\hline Involvement & $108(27.3)$ & $83(27.5)$ & $25(26.9)$ & 0.296 & 0.862 \\
\hline Be more helpful & $79(20.0)$ & $61(20.2)$ & $18(19.4)$ & & \\
\hline Be more interactive & $29(7.3)$ & $22(7.3)$ & $7(7.5)$ & & \\
\hline Broader variety of activities & $35(8.9)$ & $28(9.3)$ & $7(7.5)$ & 0.268 & 0.605 \\
\hline Getting rest & $153(38.7)$ & $115(38.1)$ & $38(40.9)$ & & \\
\hline Frequency & $30(7.6)$ & $27(8.9)$ & $3(3.2)$ & 3.309 & 0.069 \\
\hline Do more often & $30(7.6)$ & $27(8.9)$ & $3(3.2)$ & & \\
\hline Do less often & $0(0.0)$ & $0(0.0)$ & $0(0.0)$ & & \\
\hline Involvement & $133(33.8)$ & $97(32.2)$ & $26(38.7)$ & 1.395 & 0.498 \\
\hline Be more helpful & $87(22.0)$ & $63(20.9)$ & $24(25.8)$ & & \\
\hline Be more interactive & $46(11.6)$ & $34(11.3)$ & $12(12.9)$ & & \\
\hline Broader variety of activities & $22(3.5)$ & $18(6.0)$ & $4(4.3)$ & 0.372 & 0.542 \\
\hline Arts, crafts, music, and stories & $110(27.8)$ & $83(27.5)$ & $27(29.0)$ & & \\
\hline Frequency & $33(8.4)$ & $27(8.9)$ & $6(6.5)$ & 0.575 & 0.448 \\
\hline Do more often & $33(8.4)$ & $27(8.9)$ & $6(6.5)$ & & \\
\hline Do less often & $0(0.0)$ & $0(0.0)$ & $0(0.0)$ & & \\
\hline Involvement & $55(14.0)$ & $42(13.9)$ & $13(14.0)$ & 0.056 & 0.972 \\
\hline
\end{tabular}




\begin{tabular}{|c|c|c|c|c|c|}
\hline Be more helpful & $7(1.8)$ & $5(1.7)$ & $2(2.2)$ & & \\
\hline Be more interactive & $48(12.2)$ & $37(12.2)$ & $11(11.8)$ & & \\
\hline Broader variety of activities & $62(15.7)$ & $47(15.6)$ & $15(16.1)$ & 0.017 & 0.896 \\
\hline Taking care of others & $98(24.8)$ & $79(26.2)$ & $19(20.4)$ & & \\
\hline Frequency & $47(11.9)$ & $38(12.6)$ & $9(9.7)$ & 0.573 & 0.449 \\
\hline Do more often & $44(11.1)$ & 35 (11.6) & $9(9.7)$ & & \\
\hline Do less often & $3(0.8)$ & $3(1.0)$ & $0(0.0)$ & & \\
\hline Involvement & $58(14.7)$ & $47(15.6)$ & $11(11.8)$ & 1.237 & 0.539 \\
\hline Be more helpful & $40(10.1)$ & $32(10.6)$ & $8(8.6)$ & & \\
\hline Be more interactive & $18(4.6)$ & $15(5.0)$ & $3(3.2)$ & & \\
\hline Broader variety of activities & $28(7.1)$ & $25(8.3)$ & $3(3.2)$ & 2.756 & 0.097 \\
\hline House guests & $94(23.8)$ & $69(22.8)$ & $25(26.9)$ & & \\
\hline Frequency & $34(8.6)$ & $24(7.9)$ & $10(10.8)$ & 0.711 & 0.399 \\
\hline Do more often & $32(8.1)$ & $23(7.6)$ & $9(9.7)$ & & \\
\hline Do less often & $2(0.5)$ & $1(0.3)$ & $1(1.1)$ & & \\
\hline Involvement & $69(17.5)$ & $51(16.8)$ & $18(19.3)$ & 1.370 & 0.504 \\
\hline Be more helpful & $11(2.8)$ & $8(2.6)$ & $3(3.2)$ & & \\
\hline Be more interactive & $58(14.7)$ & $43(14.2)$ & $15(16.1)$ & & \\
\hline Broader variety of activities & $33(8.4)$ & $27(8.9)$ & $6(6.5)$ & 0.575 & 0.448 \\
\hline Celebrations at home & $83(21.0)$ & $59(19.5)$ & $24(25.8)$ & & \\
\hline Frequency & $18(4.6)$ & $14(4.6)$ & $4(4.3)$ & 0.018 & 0.892 \\
\hline Do more often & $18(4.6)$ & $14(4.6)$ & $4(4.3)$ & & \\
\hline Do less often & $0(0.0)$ & $0(0.0)$ & $0(0.0)$ & & \\
\hline Involvement & $70(17.7)$ & $50(16.6)$ & $20(21.6)$ & 0.990 & 0.610 \\
\hline Be more helpful & $11(2.8)$ & $9(3.0)$ & $2(2.2)$ & & \\
\hline Be more interactive & $59(14.9)$ & $41(13.6)$ & $18(19.4)$ & & \\
\hline Broader variety of activities & $28(7.1)$ & $20(6.6)$ & $8(8.6)$ & 0.423 & 0.515 \\
\hline
\end{tabular}

$* p<.004$

${ }^{\text {I }}$ Participants could select multiple responses

\section{Aim 3: Correlates of Caregiver Dissatisfaction with Young Children's Home Participation}

For the total sample, multiple linear regression was used to develop a model of caregiver dissatisfaction with young children's participation at home. As shown in Table 5 below, three of the independent variables had significant effects in the full model: delay $(p<0.001)$, household income $\geq \$ 60,001(p=0.032)$, and environmental support $(p<0.001)$. The standardized coefficient for a having a delay is $\beta=0.533$, which suggests that caregivers' dissatisfaction with their young child's participation increases by a factor of 0.533 when their child has a delay, as compared to caregivers of young children without delays. For families earning more than $\$ 60,000$ annually, caregiver dissatisfaction increases by a factor of 0.503 standard deviations with each standard deviation unit increase in income. The standardized coefficient for 
environmental support suggests that as caregiver perceptions of environmental support in the home decreases by one standard deviation, caregiver dissatisfaction with the young child's participation at home increases by a factor of 0.637 standard deviations. This eight variable model was able to account for $9.8 \%$ of the variance in caregiver dissatisfaction, which suggests poor model fit $\left(F(8,385)=5.251, p<0.001, R^{2}=.098,95 \%\right.$ CI $\left.[25.366,86.313]\right)$.

\section{Table 5}

Correlates of Caregiver Dissatisfaction with Young Children's Participation in Home Activities (Total sample $(N=395))$

\begin{tabular}{lcccc}
\hline & B & $\begin{array}{c}\text { Standard Error } \\
\text { B }\end{array}$ & $\begin{array}{c}\text { Standardized } \\
\text { Coefficient } \\
(\beta)\end{array}$ & $p$ \\
\hline Constant & 55.840 & 18.524 & -- & 0.003 \\
\hline Child factors & & & & \\
\hline Age & 1.025 & 1.372 & 0.040 & 0.455 \\
PEDI-CAT Daily activities & -0.398 & 0.265 & -0.146 & 0.134 \\
PEDI-CAT Mobility & 0.344 & 0.182 & 0.159 & 0.059 \\
PEDI-CAT Social/cognitive & 0.109 & 0.269 & 0.038 & 0.687 \\
$\quad$ Delay & 34.443 & 7.745 & 0.533 & $0.000^{* *}$ \\
\hline Family factors & & & & \\
\hline Household income & & & \\
$\quad \leq 60,000$ & 25.748 & 13.466 & 0.448 & 0.056 \\
$\quad \geq \$ 60,001$ & 28.717 & 13.387 & 0.503 & $0.032^{*}$ \\
Environmental factors & & & & $0.000^{* *}$ \\
\hline Environmental support & -1.249 & 0.234 & -0.637 & \\
\hline$* * .05$ & & & &
\end{tabular}




\section{Discussion}

Participation is an important patient-reported outcome relevant to early intervention, early childhood special education, and pediatric rehabilitation. However, participation is a complex outcome with multiple dimensions (Coster \& Khetani, 2008; Hemmingsson \& Jonsson, 2005; Imms et al., 2016; WHO, 2007), including a subjective dimension of client satisfaction with their young child's participation (Coster et al., 2012; Hammel et al., 2008). For children who are too young to self-report, estimates of caregiver satisfaction with their young child's participation in specific activities are critical to ensuring that therapies consider caregiver priorities for change. Young children spend a majority of their time at home (Hofferth \& Sandberg, 2001), and interventions involving young children often take place at home (Hebbeler et al., 2007). Hence, there is value in building knowledge about common types of caregiver priorities for change at home and associated factors that might be plausible targets for homebased interventions.

To date, the PEM approach includes two validated caregiver report questionnaires (Coster et al., 2013; Khetani et al., 2015) that afford new opportunities to feasibly build clinically relevant knowledge about caregiver satisfaction with children's participation in specific settings such as the home. Caregiver input during formative phases of instrument development guided the decision to use 'desire change' as a more concrete way of asking caregivers about their satisfaction with their child's participation in activities (Bedell et al., 2013; Coster et al., 2012; Khetani, et al., 2013a). Prior studies employing the PEM questionnaires have found that caregivers of school-aged children with disabilities are more likely to desire change in their child's participation in home, school, and community-based activities as compared to caregivers of children without disabilities, even after controlling for covariates such as age and household 
income (Bedell et al., 2013; Coster et al., 2013; Law et al., 2012a). In addition, prior studies using PEM have reported on the mediating effect of the environment on children's participation in specific settings, including the home (Anaby et al., 2014).

Few studies have extended these setting-specific findings about patterns and correlates of caregiver satisfaction with children's participation to the early childhood period (Dunst et al., 2002; Rosenberg et al., 2010a). Recently, however, Benjamin and colleagues (2016) used the YC-PEM to report on activity-specific disparities in caregiver satisfaction with young children's participation within an early childhood educational setting. To our knowledge, this is the first study to apply the YC-PEM in order to examine discrepancies and correlates of caregiver satisfaction with home participation among young children with and without delays. In the remainder of this section, each of the main study findings are discussed in detail.

\section{Aim 1: Areas of Caregiver Dissatisfaction with Young Children's Home Participation}

Caregivers sampled in this study shared similar priorities with respect to the concerns they have about their young child's participation at home. Specifically, the findings confirm the hypothesis that caregivers of young children with and without delays most often express concern in their young child's participation in non-discretionary activities such as household chores and basic care routines. For example, nearly two-thirds of caregivers of young children with and without delays desired change in the non-discretionary activity of cleaning up.

There are several ways to interpret these findings. First, engagement in household chores, such as cleaning up, is expected to help all children develop important life skills, specifically in western culture (Dunn, 2004; Dunn, Magalhaes, Mancini, 2014) and therefore may be highly prioritized by caregivers of children with and without delays (Amaral, Drummond, Coster, \& Mancini, 2014). Prior studies present mixed findings about the effect of a child's disability status 
on caregiver priorities for change in household chores. Dunn and Gardner (2013) found that both caregivers of children with and without physical disabilities reported similar levels of dissatisfaction with their child's participation in household chores. However, other studies have reported significant disability group differences in caregiver satisfaction with children's participation in household chores (Law et al., 2012a) and non-discretionary out-of-home activities among younger children (Benjamin et al., 2016; Rosenberg, Jarus, \& Bart, 2010).

In comparison to prior studies involving younger children, the lack of significant disability group differences in this study may be a function of variable caregiver expectations for younger children specific to non-discretionary activities, as younger children generally engage in fewer household tasks (Dunn \& Gardner, 2013). Alternatively, these results could indicate that, caregivers of young children with delays may have lower expectations for their child's participation in activities at home as compared to other settings, such as the daycare/preschool setting where significant differences in caregiver satisfaction between groups has been identified (Benjamin et al., 2016). Future studies could examine activity-specific group differences (delay vs. no delay) in caregiver satisfaction specific to other settings, such as school and community, in order to confirm patterns in caregiver satisfaction with their child's participation across the full range of settings that comprise everyday life for young children. This research can provide useful information to clinicians who are positioned to customize interventions in response to caregiver dissatisfaction with their young child's participation.

Alternatively, these results may reflect the priorities of caregivers who are managing home life while employed outside of the home (Bornstein \& Zlotnik, 2010; Hofferth \& Sandberg, 2001). Nearly half of the respondents (50.6\%) in this study were employed and about half of the children (50.9\%) attended childcare. This may shape a caregivers priorities for time 
use at home as well as their expectations for child engagement in non-discretionary activities like basic care routines and household chores within the time they have available (Bornstein $\&$ Zlotnik, 2010; Hofferth \& Sandberg, 2001; Larson \& Verma, 1999). Subsequent analyses of these data could include item-level analyses of YC-PEM home environmental responses in order to examine the extent to which caregivers report having adequate time to support their young child's participation at home. These data could help confirm study results about the role of environmental factors on caregiver dissatisfaction with young children's participation at home. Furthermore, the clinical utility of this knowledge would allow practitioners to modify and develop different home carry-over plans according to specific environmental constraints and supports.

\section{Aim 2: Type(s) of Caregiver Change Desired with Young Children's Home Participation}

Caregivers sampled in this study expressed more than one type of concern with their young children's participation in home activities. Due to the lack of statistically significant differences found between subgroups, results reject the hypothesis that caregivers of children with delays more often desire for their child to be more helpful and participate more frequently in home activities when compared to caregivers of children without delays. However, study results indicate potential trends in caregivers' type(s) of change desired in their young children's participation according to type of home activity (e.g., discretionary vs. non-discretionary).

Among caregivers dissatisfied with their young child's participation, caregivers most commonly expressed a desire for their child to increase their level of involvement, specifically 'be more helpful', in non-discretionary activities (i.e., basic care routines and household chores). Caregivers also reported that they wanted their young child to participate 'less often' or 'be more interactive' in discretionary (i.e. interactive and organized play and socializing with friends and 
family) home activities. This trend lends face validity to the PEM assessment approach that was guided by caregiver input about the concept of participation being context dependent (Coster et al., 2012; Khetani et al., 2013). For example, Khetani and colleagues (2013a) designed the YCPEM in response to caregiver report that "how involved" their child is when participating depended on whether the activity was done to sustain a household (non-discretionary) or for enjoyment and well-being (discretionary).

To our knowledge, this is the first study to closely examine trends in the types of caregiver change desired in young children's participation. However, prior studies that examine caregivers' desire change conclude that a higher percentage of caregivers of children with disabilities or delays desire their child's participation to change in a greater proportion of activities, which may indicate that caregivers of children with disabilities or delays perceive more activities as being problematic (Benjamin et al., 2016; Law et al., 2012a). Yet, these studies do not capture the specific type(s) of change desired by caregivers of children with and without delays. Additionally, in contrast to these studies, findings from this aim suggest that both caregivers of young children with and without delays share similar concerns in the home setting and want similar types of change in their young child's participation.

Future studies are needed to confirm these trends in type(s) of change desired by activity type (e.g., discretionary vs. non-discretionary). These studies could focus on out-of-home contexts and potentially employ alternative participation measures, such as the Assessment of Preschool Children's Participation (APCP; Law et al., 2012b). Building knowledge about patterns of type(s) of change caregivers desire in their children's participation is clinically useful because it allows practitioners to set goals and intervention plan based on which ways caregivers would like their young child's participation to change. 


\section{Aim 3: Correlates of Caregiver Dissatisfaction with Young Children's Home Participation}

Since more than half of the caregivers sampled desired changed in their young child's participation at home, we examined factors related to caregiver dissatisfaction to identify potential intervention targets specific to addressing caregiver concern at home. Results suggest that the presence of a disability or delay, earning more than $\$ 60,000$ annually, and lower environmental support were significantly associated with caregiver dissatisfaction with their young child's participation in home activities. These results reject the hypothesis that lower household income correlates with greater caregiver dissatisfaction. However, results support the hypothesis that the presence of a disability or delay and decreased environmental support correlate with increased caregiver dissatisfaction.

While models of participation have typically associated child factors to participation frequency, involvement, and/or diversity, few studies have shown correlations between child factors and caregiver satisfaction with participation (Anaby et al., 2014; Colver et al., 2012; Jarus et al., 2011; King et al., 2006; Rosenberg, Bart, Ratzon, \& Jarus, 2012; Soref et al., 2011). One of the few studies that reports findings on the correlation between child factors and caregiver satisfaction suggested that the inclusion of the child's disability status increased the explained variance in their model of participation outcomes (Rosenberg et al., 2012). This study also reported that having a child with a disability predicted lower rates of caregiver satisfaction. This literature supports study findings, which indicate that the presence of a disability or delay is associated with an increase in caregivers' desire for change. Future studies should employ the use of other indicators of disability status, such as developmental status, to understand trends in how a child's capacities relate to caregiver satisfaction with their child's participation in different settings and with different age groups. 
There is mixed evidence on the impact of household income on young children's participation outcomes (Anaby et al., 2014; Khetani et al., 2013c; Law et al., 2012b; Rosenberg et al., 2010a; Soref et al., 2011). Two studies leveraging large sample data on young children receiving early intervention services reported that caregivers earning a lower annual income were more likely to experience community participation difficulties (Khetani et al., 2013c; Khetani et al., 2012b). For example, families earning less than $\$ 25,000$ annually were more likely to report dissatisfaction with their young child's participation in $78 \%$ of community activities (Khetani et al., 2013c). In contrast, Rosenberg and colleagues (2010a) found that household income had a significant influence on participation diversity and independence level but not on caregiver satisfaction. However, results from this study suggest that an annual household income of $\$ 60,000$ or more is associated with increased caregiver dissatisfaction with young children's participation at home. Despite these findings, the income range of less than $\$ 60,000$ annually was trending with an association to caregiver dissatisfaction. Interpretation of these results lend evidence that a true association between household income and caregiver satisfaction with young children's participation is not fully understood. Future studies should continue to analyze the relationship between young children's participation outcomes and household income in order to identify whether a distinct trend exists. Specifically, future studies employing larger sample sizes could also afford examination of more than two income categories.

To our knowledge, no studies to date have evaluated the association of environmental factors on caregiver satisfaction with children's participation. However, findings from this study are congruent with prior literature on the relative influence of the child's environment on participation frequency and/or involvement (Anaby et al., 2013; Anaby et al., 2014; Khetani et al., 2012b; Rosenberg et al., 2012). One study found that environmental barriers had a direct 
influence on children's participation frequency and involvement across home, school, and community contexts and that their model explained $50 \%$ to $64 \%$ of the variance in children's participation outcomes (Anaby et al., 2012). Additionally, Rosenberg and colleagues (2012) found that environmental restrictions to participation were significantly associated with all participation outcomes, including caregiver satisfaction, but especially with objective outcomes (e.g., diversity and intensity). Similarly, results from this study indicate that environmental factors are significantly correlated with caregiver satisfaction. This further suggests that caregivers perception of environmental barriers adds too their dissatisfaction with their child's participation. Future research could examine specific environmental factors associated with participation outcomes. This type of knowledge about specific environmental impacts on caregiver satisfaction may help providers to identify modifiable targets for intervention in a specific setting or activity if a caregiver desires change because environmental factors may be more malleable to change than the child's functional capacities (Anaby et al., 2013; Law et al., 2011).

Despite these results, model fit was poor $\left(R^{2}=.098\right)$, which may be due to the fact that select independent variables (i.e., child, family, and environmental factors) included in the model have been typically correlated with participation frequency and/or involvement in prior literature, as opposed to caregiver satisfaction (Anaby et al., 2014; Colver et al., 2012; King et al., 2009; Khetani et al., 2012b; Rosenberg et al., 2012). Additionally, some select independent variables were chosen based on models of older children's participation. Therefore, the poor fit of the model could potentially be due to the fact that 1) selected independent variables do not model well with caregiver satisfaction with home participation and/or 2) caregiver expectations differ 
for home participation in early childhood as compared to middle or late childhood (Bornstein \& Zlotnik, 2010; Hofferth \& Sandberg, 2001; Khetani et al., 2015; Larson \& Verma, 1999).

Although the model was a poor fit, understanding correlations of caregiver satisfaction has important clinical implications, such as understanding factors that may influence intervention geared towards addressing caregiver concerns in participation. Therefore, further research is necessary to understand trends in how child, family, and environmental factors correlate with caregiver satisfaction. Additionally, since caregivers sampled tended to desire change in terms of involvement (Aim 2), the building and testing of a similar model of young children's home involvement is currently underway using structural equation modeling (Khetani \& Albrecht, under review). Future studies may also opt to use this participation modeling approach, by first looking for trends in types of change desired or a specific activity in which most caregivers desire change, and then modeling based on the results of those activity-specific trends.

\section{Study Limitations}

Results of this study should be considered in light of some limitations that impact the interpretability of findings. First, the use of convenience and snowball sampling strategies limit the generalizability of study findings to the larger American and Canadian populations. Specifically, the sample is fairly homogeneous with respect to household income, which may limit interpretation of Aim 3 results. Secondly, data were obtained primarily during summer months. During this season, time use at home may be more variable due to improved weather conditions as well as varied school and work schedules. Thus, the timing of data collection may influence caregiver report as the typical home activities that young children participate in during these months may differ compared to other seasons. Furthermore, missing PEDI-CAT data (29.1\%) resulted in the use of multiple imputation for Aim 3 analyses. While this approach is 
deemed most appropriate for dealing with data that is missing not at random (MNAR), there are limitations in deriving data from this statistical procedure as it may increase Type 2 error. Additionally, lack of statistically significant group differences in Aims 1 and 2 may be due to uneven sample size resulting in increased Type 2 error rate. 


\section{Conclusion}

This study extends on prior knowledge about patterns and correlates of young children's participation by examining similarities and differences in areas of caregiver dissatisfaction, types of change desired, and correlates of dissatisfaction specific to the home context. Results lend support for the likelihood that caregivers of young children with and without disabilities and delays share common expectations and concerns with young children's participation, but that there may be activity-specific trends in type(s) of concerns expressed. Results also lend support to the importance of considering child, family, and environmental factors when designing family-centered, home-based interventions targeting participation-level outcomes.

Future research is needed to understand how patterns and correlates of young children's participation differs according to child age, disability status, context (i.e., setting and activity type), and/or assessment dimension (i.e., objective vs. subjective). Additionally, future studies with larger sample sizes could examine the relative impact of specific environmental features and resources in order to gather more clinically relevant information on subsets of environmental factors to target for intervention planning purposes. Knowledge about specific environmental factors may help providers to identify modifiable targets for intervention in a specific setting or activity if a caregiver desires change. Current work is underway to build and test a similar model of young children's participation, specifically on the dimension of home involvement, results of which can extend knowledge about potential intervention targets. 


\section{References}

American Occupational Therapy Association (AOTA). (n.d.). Occupational Therapy for Young Children: Birth though 5 years of age. Retrieved from http://www.aota.org/ media/Corporate/Files/AboutOT/Professionals/WhatIsOT/CY/FactSheets/FactSheetOT forYoungChildren.pdf\#sthash.uZ6RFGaV.dpuf

Anaby, D., Hand, C., Bradley, L., Direzze, B., Forhan, M., DiGiacomo, A., \& Law, M. (2013). The effect of the environment on participation of children and youth with disabilities: A scoping review. Disability and Rehabilitation, 35(19), 1589-1598.

Anaby, D., Law, M., Coster, W., Bedell, G., Khetani, M., Avery, L., \& Teplicky, R. (2014). The mediating role of the environment in explaining participation of children with youth with and without disabilities across home, school, and community. Archives of Physical Medicine and Rehabilitation, 95, 908-917.

AOTA. (2014). Occupational Therapy Practice Framework: Domain and Process $3^{\text {rd }}$ Edition. American Journal of Occupational Therapy, 68(Supplement 1), S1-S48.

Baraldi, A. N. \& Enders, C. K. (2010). An introduction to modern missing data analyses. Journal of School Psychology, 48, 5-37.

Beckung, E. \& Hagberg, G. (2002). Neuroimpairments, activity limitations, and participation restrictions in children with cerebral palsy. Developmental Medicine \& Child Neurology, 44, 309-316.

Bedell, G. (2009). Further validation of the Child and Adolescent Scale of Participation (CASP). Developmental Neurorehabilitaiton, 12(5), 342-351.

Bedell, G. M., Coster, W. J., Law, M. C., Liljenquist, K., Kao, Y-C, Teplicky, R,... Khetani, M. A. (2013). Community participation, supports and barriers of school age children with 
and without disabilities. Archives of Physical Medicine and Rehabilitation, 94(2), 315323.

Bedell, G. M., Khetani, M. A., Coster, W. J., Law, M. \& Cousins, M. (2012). Community, social, and civic life. In A. Majnemer (Ed.), Clinical and research measures for children with developmental disabilities: Framed by the ICF-CY. (pp. 416-432). Mac Keith Press.

Bedell, G. M., Khetani, M. A., Cousins, M. A., Coster, W. J., \& Law, M. C. (2011). Parent perspectives to inform development of measures of children's participation and environment. Archives of Physical Medicine and Rehabilitation, 92, 765-773.

Bedell, G. \& McDougall, J. (2013). The Child and Adolescent Scale of Environment (CASE): Further validation with youth who have chronic conditions. Developmental Neurorehabilitaiton. doi: 10.3109/17518423.2013.855273

Benjamin, T., Lucas-Thompson, R. G., Little, L. M., Davies, P., \& Khetani, M. (2016). Participation in early childhood educational environments for young children with and without developmental disabilities and delays: A mixed methods study. Physical and Occupational Therapy in Pediatrics. doi: 10.3109/01942638.2015.1130007

Bornstein, M. H. \& Zlotnik, D. (2009). Parenting styles and their effects. In J. B. Benson \& M. M. Haith (Eds.), Social and Emotional Development in Infancy and Early Childhood (pp. 280-293). Oxford, UK: Academic Press.

Bronfenbrenner, U. (1994). Ecological models of human development. International Encyclopedia of Education, 3(2), 1643-1647.

Buchner, A., Erdfelder, E., Faul, F., \& Lang, A. -G. (2013). G*Power 3.1.9.2 [computer software]. Heinrich-Heine-Universität Düsseldorf.

Classen, S. (2006). Study Designs for Secondary Analysis of Existing Data. In G. Kielhofner 
(Ed.), Research in Occupational Therapy: Methods of Inquiry for Enhancing Practice (pp. 111-126). FA Davis Company: Philadelphia, PA.

Colver, A., Thyen, U., Arnaud, C, Beckung, E., Fauconnier, J., Marcelli, M.,... Dickinson, H. O. (2012). Association between participation in life situations of children with cerebral palsy and their physical, social, and attitudinal environment: A cross-sectional multicenter European study. Archives of Physical Medicine and Rehabilitation, 93, 21542164.

Coster, W. \& Khetani, M. A. (2008). Measuring participation of children with disabilities: Issues and challenges. Disability and Rehabilitation, 30(8), 639-648.

Coster, W. J., Deeney, T., Haltiwanger, J., \& Haley, S. M. (1998). School Function Assessment (SFA). San Antonio, TX: PsychCorp.

Coster, W. J., Law, M. C., \& Bedell, G. M. (2010). Participation and Environment Measure for Children and Youth (PEM-CY). Boston, MA: Boston University.

Coster, W., Law, M., Bedell, G., Liljenquist, K., Kao, T. -C., Khetani, M., \& Teplicky, R. (2013). School participation, supports and barriers of students with and without disabilities. Child: Care, Health and Development, 39(4), 535-543.

Coster, W., Law, M., Bedell, G., Khetani, M., Cousins, M., \& Teplicky, R. (2012). Development of the participation and environment measure for children and youth: conceptual basis. Disability \& Rehabilitation, 34(4), 238-246.

Daunhauer, L., Gerlach-McDonald, B., \& Khetani, M.A. (2014). Rules of "engagement": Addressing participation and functional performance in children with intellectual and developmental disabilities. In R. Hodapp (Ed.), International Review of Research in Developmental Disabilities (pp. 151-184). Elsevier Inc. 
Dumas, H. M., Fragala-Pinkham, M. A., Haley, S. M., Ni, P., Coster, W., Kramer, J. M.... Ludlow, L. H. (2012). Computer adaptive test performance in children with and without disabilities: prospective field study of the PEDI-CAT. Disability \& Rehabilitation, 34(5), 393-401.

Dunn, L. \& Gardner, J. (2013). Household task participation of children with and without physical disability. American Journal of Occupational Therapy, 67(5), e100-e105.

Dunst, C. J., Hamby, D., Trivette, C. M., Raab, M., \& Bruder, M. B. (2002). Young children's participation in everyday family and community activity. Psychological Reports, 91, 875897.

Enders, C. K. (2010). Applied missing data analysis. Guilford Press: New York, NY.

Engel-Yeger, B. \& Hamed-Daher, S. (2013). Comparing participation in out of school activities between children with visual impairments, children with hearing impairments and typical peers. Research in Developmental Disabilities, 34, 3124-3132.

Eyssen, I. C., Steultjens, M. P., Dekker, J., \& Terwee, C. B. (2011). A systematic review of instruments assessing participation: Challenges in defining participation. Archives of Physical Medicine and Rehabilitation, 92, 983-997.

Field, A. (2014). Discovering Statistics Using IBM SPSS Statistics $4^{\text {th }}$ Edition. SAGE Publications.

Haley, S. M., Coster, W. J., Dumas, H. M., Fragala-Pinkham, M. A., Ni, P. S., Kramer, J.,... Ludlow, L. H. (2011). Accuracy and precision of the Pediatric Evaluation of Disability Inventory computer adaptive tests (PEDI-CAT). Developmental Medicine \& Child Neurology, 53(12), 1100-1106.

Haley, S. M., Coster, W. J., Ludlow, L. H., Haltiwagner, J. T., \& Andrellos, P. J. (1992). 
Pediatric Evaluation of Disability Inventory (PEDI). Boston, MA: New England Medical Center Hospitals.

Hammel, J., Magasi, S., Heinemann, A., Whiteneck, G., Bogner, J., \& Rodriguez, E. (2008). What does participation mean? An insider perspective from people with disabilities. Disability \& Rehabilitation, 30(19), 1445-1460.

Hebbeler, K., Spiker, D., Bailey, D., Scarborough, A., Mallik, S., Simeonsson, R.,... Nelson, L. (2007). Final report of the National Early Intervention Longitudinal Study (NEILS). Menlo Park, CA: SRI International. Available from https://docs.google.com/viewer?url=http\%3A\%2F\%2Fwww.sri.com\%2Fsites\%2Fdefault \%2Ffiles\%2Fpublications\%2Fneils_finalreport_200702.pdf

Hemmingsson, H. \& Jonsson, H. (2005). An occupational perspective on the concept of participation in the International Classification of Functioning, Disability, and Health-Some critical remarks. American Journal of Occupational Therapy, 59(5), 569-576.

Henry, K. L. (2015). Categorical X [PDF document]. Retrieved from (personal communication, E. Albrecht, January 29, 2016).

Hilton, C. L., Crouch, M. C., \& Isreal, H. (2008). Out-of-school participation patterns in children with high-functioning autism spectrum disorders. American Journal of Occupational Therapy, 62, 554-563.

Hofferth, S. L. \& Sandberg, J. F. (2001). How American children spend their time. Journal of Marriage and Family, 63, 295-308.

IBM. (2011). IBM SPSS Missing Values 20. Retrieved from https://www.csun.edu/sites/default/files/missing-values20-64bit.pdf IBM. (2014). SPSS, Inc. (Version 23.0) [computer software]. IBM: Chicago, IL 
Imms, C., Adair, B., Keen, D., Ullenhag, A., Rosenbaum, P., \& Granlund, M. (2016).

'Participation': A systematic review of language, definitions, and constructs used in intervention research with children with disabilities. Developmental Medicine \& Child Neurology, 58(1), 29-38.

Individuals with Disabilities Education Improvement Act of 2004, 20 U.S.C. $\S 1400$ et seq. Retrieved from http://www.gpo.gov/fdsys/pkg/PLAW-108publ446/html/PLAW108publ446.htm

Jarus, T., Anaby, D., Bart, O., Engel-Yeger, B., \& Law, M. (2010). Childhood participation in after-school activities: What is to be expected? British Journal of Occupational Therapy, 73(8), 344-350.

Jarus, T., Lourie-Gelberg, Y., Engel-Yeger, B., \& Bart, O. (2011) Participation patterns of school-aged children with and without DCD. Research in Developmental Disabilities, 32, 1323-1331.

Khetani, M. A. (2015). Validation of environmental content in the Young Children's Participation and Environment Measure. Archives of Physical Medicine and Rehabilitation. doi: 10.1016/j.apmr

Khetani, M. A. \& Albrecht, E. (under review). Environmental impact on young children's participation in home-based activities. Developmental Medicine and Child Neurology.

Khetani, M. A., Bedell, G. M., Coster, W. J., Cousins, M., \& Law, M. (2012a). Physical, social, and attitudinal environment. In A. Majnemer (Ed.), Clinical and research measures for children with developmental disabilities: Framed by the ICF-CY (pp. 440-454). Mac Keith Press.

Khetani, M. A., Cliff, A. B., Schelly, C., Daunhauer, L., \& Anaby, D. (2014). Decisional support 
algorithm for collaborative care planning using the Participation and Environment Measure for Children and Youth (PEM-CY): A mixed methods study. Physical and Occupational Therapy in Pediatrics. doi:10.3109/01942638.2014.899288.

Khetani, M. A., Cohn, E. S., Orsmond, G. I., Law, M. C., \& Coster, W. J. (2013a). Parent perspectives of participation in home and community activities when receiving Part C early intervention services. Topics in Early Childhood Special Education, 32(4), 234-245.

Khetani, M. A. \& Coster, W. J. (2014). Social Participation. In Schell, Gillen, \& Scaffa (Eds.), Willard and Spackman's Occupational Therapy (12th edition) (pp. 731-744). Lippincott, Williams and Wilkins.

Khetani, M. A., Coster, W., Law, M., \& Bedell, G. M. (2013b). Young Children's Participation and Environment Measure (YC-PEM). Fort Collins (CO): Colorado State University.

Khetani, M., Graham, J. E., \& Alvord, C. (2013c). Community participation patterns among preschool-aged children who have received Part C early intervention services. Child: Care, Health and Development, 39(4), 490-499.

Khetani, M. A., Graham, J., Davies, P., Law, M., \& Simeonsson, R. (2015). Psychometric Properties of the Young Children's Participation and Environment Measure Archives of Physical Medicine and Rehabilitation, 96, 307-316.

Khetani, M.A., Marley, J., Baker, M., Albrecht, E., Bedell, G., Coster, W., Anaby, D., \& Law, M. (2013d). Validity of the Participation and Environment Measure for Children and Youth (PEM-CY) for Health Impact Assessment (HIA) in sustainable development projects. Disability and Health Journal, 7, 226-235. doi: 10.1016/j.dhjo.2013.11.003.

Khetani, M., Orsmond, G., Cohn, E., Law, M., \& Coster, W. (2012b). Correlates of community participation among families transitioning from Part $\mathrm{C}$ early intervention services. OTJR: 
Occupation, Participation, and Health, 32, 61-72.

Kielhofner, G. (2006). Research in Occupational Therapy: Methods of Inquiry for Enhancing Practice. F. A. Davis Company: Philadelphia, PA.

King, G. (2013). Perspectives on measuring participation: Going forward. Child: Care, Health, and Development, 39(4), 466-469.

King, G., Law, M., Hanna, S., King, S., Hurley, P., Rosenbaum, P.,... Petrenchik, T. (2006). Correlates of the leisure and recreation participation of children with physical disabilities: a structural equation modeling analysis. Children's Health Care, 35(3), 209-234.

King, G., Law, M., King, S., Hurley, P., Hanna, S., Kertoy, M.,... Young, N. (2004). Children's Assessment of Participation and Enjoyment (CAPE) and Preferences for Activities of Children (PAC). San Antonio, TX: Harcourt Assessment, Inc.

King, G., Law, M., King, S., Rosenbaum, P., Kertoy, M K., \& Young, N.L. (2003). A conceptual model of the factors affecting the recreation and leisure participation of children with disabilities. Physical and Occupational Therapy in Pediatrics, 23(1), 63-89.

King, G., McDougall, J., DeWit, D., Petrenchik, T., Hurley, P., \& Law, M. (2009). Correlates of change over time in the activity participation of children and youth with physical disabilities. Child Health Care, 38(4), 321-351.

Larson, R. W. (2000). Toward a psychology of positive youth development. American Psychologist, 55(1), 170-183.

Larson, R. W. \& Verma, S. (1999). How children and adolescents spend time across the world: Work, play, and developmental opportunities. Psychological Bulletin, 125(6), 701-736.

Law, M. (2002). Participation in the occupations of everday life. American Journal of Occupational Therapy, 56(6), 640-649. 
Law, M., Anaby, D., Teplicky, R., Khetani, M. A., Coster, W., \& Bedell, G. (2012a).

Participation in the home environment among children and youth with and without disabilities. British Journal of Occupational Therapy (Special Issue), 76(2), 58-66.

Law, M. C., Darrah, J., Pollock, N., Wilson, B., Russell, D. J., Walter, S. D., ... \& Galuppi, B. (2011). Focus on function: a cluster, randomized controlled trial comparing child-versus context-focused intervention for young children with cerebral palsy. Developmental Medicine \& Child Neurology, 53(7), 621-629.

Law, M., Finkelman, S., Hurley, P., Rosenbaum, P., King, S., King, G., \& Hanna, S. (2004). Participation of children with physical disabilities: Relationships with diagnosis, physical functioning, and demographics. Scandinavian Journal of Occupational Therapy, 11, 156162.

Law, M., Haight, M., Milroy, B., Willms, D., Stewart, S., \& Rosenbaum, P. (1999). Environmental factors affecting the occupations of children with physical disabilities. Journal of Occupational Science, 6(3), 102-110.

Law, M., King, G., King, S., Kertoy, M., Hurley, P., Rosenbaum, P.,... Hanna, S. (2006). Patterns of participation in recreational and leisure activities among children with complex physical disabilities. Developmental Medicine \& Child Neurology, 48, 337-342.

Law, M., King, G., Petrenchik, T., Kertoy, M., \& Anaby, D. (2012b). The Assessment of Preschool Children's Participation: Internal consistency and construct validity. Physical and Occupational Therapy in Pediatrics, 32(3), 272-287.

Law, M., Petrenchik, T., King, G., \& Hurley, P. (2007). Perceived environmental barriers to recreational, community, and school participation for children and youth with physical disabilities. Archives of Physical Medicine and Rehabilitation, 88, 1636-1642. 
Majnemer, A. (2009). Promoting participation in leisure activities: Expanding role for pediatric therapists. Physical and Occupational Therapy in Pediatrics, 29(1), 1-5.

Mancini, M. C., Coster, W. J., Trombly, C. A., \& Heeren, T. C. (2000). Predicting elementary school participation in children with disabilities. Archives of Physical Medicine and Rehabilitation, 81, 339-347.

Mandich, A., Polatakjko, H., Miller, L. \& Baum, C. (2004). The Pediatric Activity Card Sort (PACS). Ottowa, ON: Canadian Association of Occupational Therapists.

McCauley, D., Gorter, J. W., Russell, D. J., Rosenbaum, P., Law, M., \& Kertoy, M. (2013). Assessment of environmental factors in disabled children 2-12 years: Development and reliability of the Craig Hospital Inventory of Environmental Factors (CHIEF) for Children-Parent Version. Child: Care, Health and Development, 39(3), 337-344.

McConachie, H., Colver, A., Forsyth, R., Jarvis, S., \& Parkinson, K. (2006). Participation of disabled children: How should it be characterised and measured? Disability \& Rehabilitation, 28(18), 1157-1164.

National Board for Certification in Occupational Therapy (NBCOT). (2012). Practice analysis of the occupational therapist registered. Retrieved from http://www.nbcot.org/exam blueprints

Orlin, M. N., Palisano, R. J., Chiarello, L. A., Kang, L.-J., Polansky, M., Almasri, N., \& Maggs, J. (2010). Participation in home, extracurricular, and community activities among children and young people with cerebral palsy. Developmental Medicine and Child Neurology, 52, 160-166.

Osborne, J. W. (2013). Best Practices in Data Cleaning. SAGE Publications.

Phillips, R. \& Hogan, A. (2014). Recreational participation and the development of social 
competence in preschool aged children with disabilities: A cross sectional study. Disability and Rehabilitation.

Rosenberg, L., Bart, O., Ratzon, N. Z., \& Jarus, T. (2012). Personal and environmental factors predict participation of children with and without mild developmental disabilities. Journal of Child and Family Studies. doi: 10.1007/s10826-012-9619-8

Rosenberg, L., Jarus, T., \& Bart, O. (2010a). Development and initial validation of the Children Participation Questionnaire (CPQ). Disability and Rehabilitation, 32(20), 1633-1644.

Rosenberg, L., Ratzon, N. Z., Jarus, T., \& Bart, O. (2010b). Development and initial validation of the Environmental Restriction Questionnaire (ERQ). Research in Developmental Disabilities, 31, 1323-1331.

Soref, B., Ratzon, N. Z., Rosenberg, L., Leitner, T., Jarus, T., \& Bart, O. (2011). Personal and environmental pathways to participation in young children with and without mild motor disabilities. Child: Care, Health and Development, 38(4), 561-571.

The United Nations Children's Fund (UNICEF) (2013). The state of the world's children. Retrieved from http://www.unicef.org/sowc2013/files/SWCR2013_ENG_Lo_res_ 24_Apr_2013.pdf

Trevlas, E., Matsouka, O., \& Zachopoulou, E. (2003). Relationship between playfulness and motor creativity in preschool children. Early Child Development and Care, 173(5), $535-543$

Tsang, W. W. N., Guo, X., Fong, S. S. M., Mak, K. -K., \& Pang, M. Y. C. (2012). Activity participation intensity is associated with skeletal development in pre-pubertal children with developmental coordination disorder. Research in Developmental Disabilities, 33, 1898-1904. 
Ullenhad, A., Krumlinde-Sundholm, L., Granlund, M., \& Almqvist, L. (2014). Differences in patterns of participation in leisure activities in Swedish children with and without disabilities. Disability and Rehabilitation, 36(6), 464-471.

Wade, D. \& Halligan, P. (2007). Social roles and long-term illness: Is it time to rehabilitate convalescence? Clinical Rehabilitation, 27, 291-298.

Whiteneck, G., Charlifue, S., Gerhart, K., Overholser, J., \& Richardson, G. (1992). Quantifying handicap: A new measure of long-term rehabilitation outcomes. Archives of Physical Medicine and Rehabilitation, 73, 519-526.

Whiteneck, G. \& Dijkers, M. P. (2009). Difficult to measure constructs: Conceptual and methodological issues concerning participation and environmental factors. Archives of Physical Medicine and Rehabilitation, 90(Supplement 1), S22-S35.

WHO \& The World Bank. (2011). World Report on Disability. WHO Library Cataloguing-in Publication Data. Retrieved from http://whqlibdoc.who.int/publications/2011/978924068 5215_eng.pdf

WHO. (2001). International Classification of Functioning, Disability and Health (ICF). Geneva, Switzerland: WHO.

WHO. (2007). International Classification of Functioning, Disability, and Health: Children and Youth Version (ICF-CY). Geneva, Switzerland: World Health Organization Press, WHO. 


\section{Appendix A}

Excerpt of the YC-PEM Home Participation Section

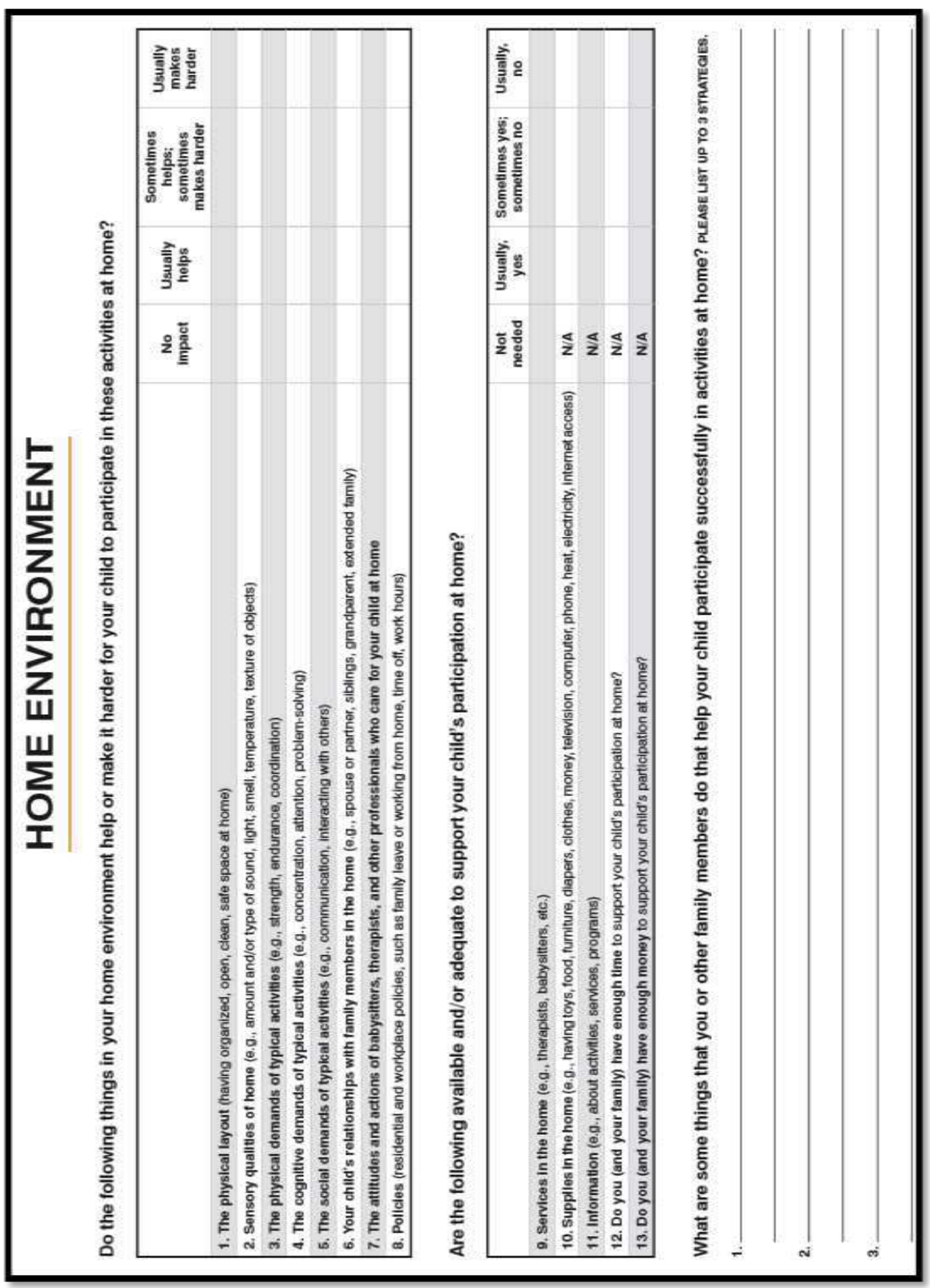




\section{Appendix B}

Variable Map

\begin{tabular}{|c|c|c|c|c|}
\hline Variable & Item Description (dataset variable name) & Correlate & Demographic & Response \\
\hline \multirow[t]{2}{*}{$\begin{array}{l}\text { Service } \\
\text { Utilization }\end{array}$} & $\begin{array}{l}\text { Does your child currently receive early } \\
\text { intervention or early childhood special education } \\
\text { services? }\end{array}$ & $\checkmark$ & $\checkmark$ & $\begin{array}{l}\text { Yes, No (if "Yes", } \\
\text { participant was placed in } \\
\text { the 'delay' subgroup; if } \\
\text { "No", participant was } \\
\text { placed in the 'no delay' } \\
\text { subgroup) }\end{array}$ \\
\hline & $\begin{array}{l}\text { Speech and language therapy } \\
\text { Occupational Therapy } \\
\text { Physical Therapy } \\
\text { Medical/private specialized preschool progra } \\
\text { Public special education preschool } \\
\text { Other therapy/services (please specify) }\end{array}$ & & $\checkmark$ & $\begin{array}{l}\text { Yes, No (if "Yes", } \\
\text { participants included } \\
\text { hours/week as well) }\end{array}$ \\
\hline $\begin{array}{l}\text { Child's } \\
\text { Functional } \\
\text { Capacities }\end{array}$ & $\begin{array}{l}\text { Please indicate if your child has difficulty in the } \\
\text { following ways: } \\
\text { Mobility } \\
\text { Processing information } \\
\text { Seeing } \\
\text { Hearing } \\
\text { Communicating with others } \\
\text { Self-feeding } \\
\text { Bladder and bowel control } \\
\text { Paying attention } \\
\text { Safety awareness } \\
\text { Controlling behavior } \\
\text { Managing emotions } \\
\text { Reacting to sensations }\end{array}$ & & $\checkmark$ & $\begin{array}{l}\text { 3-point scale (no problem, } \\
\text { little problem, big problem) }\end{array}$ \\
\hline Child's & Daily activities & $\checkmark$ & & 5-point scale (don't know, \\
\hline
\end{tabular}




\begin{tabular}{|c|c|c|c|c|}
\hline $\begin{array}{l}\text { Functional Task } \\
\text { Performance } \\
\text { (PEDI-CAT) }\end{array}$ & $\begin{array}{l}\text { Mobility } \\
\text { Social/Cognitive }\end{array}$ & & & $\begin{array}{l}\text { easy to do, needs a little } \\
\text { help, needs a lot of help, } \\
\text { unable to do) }\end{array}$ \\
\hline \multirow[t]{6}{*}{$\begin{array}{l}\text { Child and } \\
\text { Family } \\
\text { Factors }\end{array}$} & Do you currently work for pay? & & $\checkmark$ & $\begin{array}{l}\text { Nominal, } 6 \text { options (can be } \\
\text { dichotomized to yes/no or } \\
\text { collapsed to } 3 \text { point scale: } \\
\text { full time, part time, no) }\end{array}$ \\
\hline & $\begin{array}{l}\text { Which category listed below represents your total } \\
\text { family income before taxes? Please include } \\
\text { income from sources such as wages, salaries, } \\
\text { commissions, pensions, rental income and so forth. } \\
\text { Note: If parents are divorced and child lives in } \\
\text { both families, then record the income of both } \\
\text { households separately. }\end{array}$ & $\checkmark$ & $\checkmark$ & $\begin{array}{l}16 \text { possible categories } \\
(<\$ 5,000 \text { to }>\$ 100,000)\end{array}$ \\
\hline & Where were you born (State/Province/Country)? & & $\checkmark$ & $\begin{array}{l}7 \text { categories (West, } \\
\text { Midwest, South, Northeast, } \\
\text { Ontario, New Brunswick, } \\
\text { Nova Scotia) }\end{array}$ \\
\hline & What is your child's date of birth? & $\checkmark$ & $\checkmark$ & 1-71 months \\
\hline & $\begin{array}{l}\text { What is your current childcare arrangement? } \\
\text { Check ALL that apply: } \\
\text { Child is cared for by parent/legal guardian or } \\
\text { extended family member(s) during the day } \\
\text { Center-Based Program } \\
\text { (Daycare/Preschool/Nursery School) } \\
\text { Family Daycare (childcare provided in a person's } \\
\text { home) } \\
\text { Parent Cooperative Nursery School } \\
\text { In-Home Provider (e.g., nanny, au-pair) } \\
\text { Kindergarten } \\
\text { Other, please specify }\end{array}$ & & $\checkmark$ & $\begin{array}{l}4 \text { categories (parent, } \\
\text { daycare/preschool/kinderga } \\
\text { rten, in-home provider, } \\
\text { family daycare/cooperative, } \\
\text { other) }\end{array}$ \\
\hline & Child's race & & $\checkmark$ & $\begin{array}{l}6 \text { categories (American } \\
\text { Indian/Alaskan Native, }\end{array}$ \\
\hline
\end{tabular}




\begin{tabular}{|c|c|c|c|}
\hline & & & $\begin{array}{l}\text { Asian, Black or African } \\
\text { American, White, } \\
\text { Multiracial, Other) }\end{array}$ \\
\hline \multirow[t]{2}{*}{$\begin{array}{l}\text { Environmental } \\
\text { items }\end{array}$} & $\begin{array}{l}\text { Do the following things in your home environment } \\
\text { help or make it harder for your child to participate } \\
\text { in these activities at home? } \\
\text { The physical layout (eg., having organized, open, } \\
\text { clean, safe space at home) } \\
\text { Sensory qualities (e.g., amount and/or type of } \\
\text { sound, light, smell, temperature, texture of objects) } \\
\text { Physical demands of activity (e.g., strength, } \\
\text { endurance, coordination) } \\
\text { Cognitive demands of activity (e.g., concentration, } \\
\text { attention, problem-solving) } \\
\text { Social demands of activity (e.g., communication, } \\
\text { interacting with others) } \\
\text { Child's relationships with family members (spouse } \\
\text { or partner, siblings, grandparent, extended family) } \\
\text { Attitudes and actions of babysitters, therapists, and } \\
\text { other professionals who care for your child } \\
\text { Policies (eg., residential and workplace policies, } \\
\text { such as family leave or working from home, time } \\
\text { off, work hours) }\end{array}$ & $\checkmark$ & $\begin{array}{l}\text { 4-point scale (no impact, } \\
\text { usually helps, sometimes } \\
\text { helps/sometimes makes } \\
\text { harder, usually makes } \\
\text { harder) }\end{array}$ \\
\hline & $\begin{array}{l}\text { Are the following available and/or adequate to } \\
\text { support your child's participation at home? } \\
\text { Services (e.g., therapists, babysitters, etc.) } \\
\text { Supplies (eg., having toys, food, furniture, diapers, } \\
\text { clothes, money, television, computer, phone, heat, } \\
\text { electricity, internet access) } \\
\text { Information (e.g., about activities, services, } \\
\text { programs) }\end{array}$ & $\checkmark$ & $\begin{array}{l}\text { 4-point scale (not needed, } \\
\text { usually yes, sometimes } \\
\text { yes/sometimes no, usually } \\
\text { no) }\end{array}$ \\
\hline
\end{tabular}




\begin{tabular}{|c|c|c|c|c|}
\hline & $\begin{array}{l}\text { Time } \\
\text { Money }\end{array}$ & & & \\
\hline $\begin{array}{l}\text { Caregiver's } \\
\text { Desire for } \\
\text { Change }\end{array}$ & $\begin{array}{l}\text { Would you like your child's participation to } \\
\text { change in this type of home activity? } \\
\text { Getting rest } \\
\text { Personal care } \\
\text { Getting clean } \\
\text { Mealtime } \\
\text { Cleaning up } \\
\text { Meal preparation } \\
\text { Taking care of other family members } \\
\text { Laundry and dishes } \\
\text { Arts, crafts, stories, music } \\
\text { Screen time } \\
\text { Indoor play and games } \\
\text { Celebrations at home } \\
\text { House guests }\end{array}$ & -- & -- & $\begin{array}{l}\text { Yes, No (if "Yes", } \\
\text { participants specified type } \\
\text { of change desired: do more } \\
\text { often, do less often, be } \\
\text { more interactive, be more } \\
\text { helpful, and/or participate } \\
\text { in a broader variety of } \\
\text { activities) }\end{array}$ \\
\hline
\end{tabular}

